AperTO - Archivio Istituzionale Open Access dell'Università di Torino

\title{
Polyphenolic diversity in Vitis sp. leaves
}

\section{This is the author's manuscript}

Original Citation:

\section{Availability:}

This version is available http://hdl.handle.net/2318/1704440

since 2020-04-01T15:38:32Z

Published version:

DOI:10.1016/j.scienta.2019.108569

Terms of use:

Open Access

Anyone can freely access the full text of works made available as "Open Access". Works made available under a Creative Commons license can be used according to the terms and conditions of said license. Use of all other works requires consent of the right holder (author or publisher) if not exempted from copyright protection by the applicable law. 
1 Polyphenolic diversity in Vitis sp. leaves

2

3

4

5

6

7

8

9

Olga Kedrina-Okutan ${ }^{1}$, Vittorino Novello ${ }^{1}$, Thomas Hoffmann ${ }^{2}$, Johannes Hadersdorfer ${ }^{3}$, Anna

Schneider ${ }^{4}$, Wilfried Schwab ${ }^{2}$, and Alessandra Ferrandino ${ }^{1 *}$

${ }^{1}$ Dipartimento Scienze Agrarie, Forestali, Alimentari (DISAFA), Università degli Studi di Torino,

Largo P. Braccini, 2 10095, Grugliasco (TO), Italy.

${ }^{2}$ Biotechnology of Natural Products, Technical University Munich, Liesel-Beckmann-Str. 1, Freising 85354, Germany.

${ }^{3}$ Fruit Science, Technical University Munich, Dürnast 2, Freising 85354, Germany.

${ }^{4}$ Istituto Protezione Sostenibile delle Piante (IPSP), CNR, Strada delle Cacce, 73, 10135 Torino (TO), Italy.

*corresponding author: tel. +39-011-6708755; email: alessandra.ferrandino@ unito.it 


\section{ABSTRACT}

We identified and quantified the main constitutive polyphenolic compounds of the leaves of seven Vitis species and of one interspecific cross, analysing leaf blades and veins separately, to spread light on the strategic localization of polyphenols in leaf tissues. To the best to our knowledge, the main leaf constitutive polyphenols of $V$. candicans, $V$. coignetiae, $V$. vinifera sylvestris and Börner were never described. $V$. riparia and $V$. rupestris (belonging to the same botanical series of Ripariae) displayed similar flavan-3-ol and dimeric proanthocyanidin concentration and similar percentage incidence of caftaric acid over total phenolic acids. $V$. riparia distinguished respect to the other genotypes for its high flavonol content, the highest percentage incidence of myricetin derivatives and an important diversification in the type of accumulated flavonol. V. berlandieri (series Cinereae) and Börner (hybrid of $V$. riparia $\mathrm{x} V$. cinerea) accumulated low amounts of flavonol-glucosides comparing to the other species, but they showed a wide profile diversification, as well. However, it was $V . v$. sylvestris, the wild ancestor of Vitis vinifera subsp. sativa that displayed the widest flavonol profile diversification. The differences in the flavonol profile could be related to the genus Vitis evolution: in fact, with domestication, the flavonoid biosynthetic pathway underwent a progressive simplification; for this, the highest flavonol diversity found in Vitis v. sylvestris is probably a demonstration of its reduced or nil level of domestication. V. amurensis, known for its cold tolerance and resistance to downy mildew, anthracnose and white rot, markedly differentiated respect to the other genotypes, for its high concentration of polyphenols, particularly of vein flavonols and flavanonols. Moreover, V. amurensis leaves generally presented a constantly high concentration of constitutive polyphenols throughout the season that probably contributes to protect against adverse environmental condition. The abundance of polyphenols in $V$. amurensis leaves emphasizes that this species is a source of natural bioactive compounds that could find application for nutraceutical and pharmacological uses. $V$. berlandieri and Börner markedly distinguished respect to the other studied species for their exclusive capability to accumulate flavones (mainly orientin, isoorientin, vitexin and isovitexin) in blades and in veins, in considerable amounts. 

related molecules involved in the plant-defense mechanisms, to the chemotaxonomy of the genus Vitis, to the possibility of identifying specific natural bioactive compounds to use in plant-based preparation

57 for nutraceutical, cosmetic, feed/food-additive purposes.

58

59 KEYWORDS: V. amurensis, $V$. candicans, $V$, riparia, $V$. rupestris, $V$. berlandieri, $V$. coignetiae, $V$.

60 vinifera sylvestris, Börner.

61 


\section{INTRODUCTION}

The genus Vitis comprises more than 60 species, mostly inhabiting temperate regions. The most known and economically important one is the western Eurasian species Vitis vinifera subsp. vinifera, which ancestor is the wild Vitis vinifera subsp. sylvestris, naturally occurring in Europe, Middle East and Northern Africa. Up to thirty grapevine species are native of East Asia and North America, areas that host a wide diversity of Vitis species (Wan et al., 2013).

Vitis vinifera is susceptible to many pests. Phylloxera (Daktulosphaira vitifoliae), downy and powdery mildew (caused by Plasmopara viticola and Erysiphe necator, respectively), imported almost simultaneously from North America to Europe in the XIX century, are among those causing important economic loss in viticulture. Viticulturists, technicians and researchers overcame the problem tied to vinifera sensitiveness to Phylloxera by using American species or their hybrids as rootstocks. Furthermore, the introduction of downy and powdery mildew pushed to develop breeding programs based on the constitution of interspecific crosses vinifera-American species that, together with Asian species, were disease-tolerant or resistant due to their coevolution with the pathogen. Vitis species such as $V$. riparia, $V$. rupestris, $V$. californica and $V$. amurensis are known as highly tolerant to downy mildew (Gómez-Zeledón et al., 2013; Jürges et al., 2009); V. riparia, V. munsoniana, V. candicans, V. rotundifolia as highly resistant to powdery mildew (Staudt, 1997; Wan et al., 2007) and V. rotundifolia (subspecies Muscadinia) and V. arizonica as resistant to Pierce's disease (Ruel and Walker, 2006). Besides, some species distinguish for their tolerance to environmental stressors thanks to their origin: it is the case of $V$. amurensis, native of cold areas in northeastern China and Russian Siberia, that is highly frost tolerant (Zhang et al., 2012).

To prevent disease or damage caused by biotic or abiotic stresses, plants employ a complex defense system, which involves a broad spectrum of physical and biochemical changes. Biochemical resistance, such as preformed defenses, has evolved to face environmental stressors and is also related, among others, to secondary metabolites, including polyphenols (reviewed in Llorens et al., 2017 and in Dixon, 2001). Vitis vinifera is known for its abundance and richness in polyphenols that have been and 
currently are widely studied in the berries due to their implications in the technology of winemaking and in the quality of derived wines. Thousands of scientific studies were devoted to define the polyphenolic composition of Vitis vinifera berries, and, to a much lesser extent, to vegetative organs; oppositely, less is known about other Vitis species polyphenolic composition, particularly as to vegetative organs. Moore and Giannasi (1994) described the qualitative composition of flavonols and flavones in leaves of some North American Vitis species. Flavonol profiles were described also in V. amurensis (Hmamouchi et al., 1996) and V. rotundifolia (Pastrana-Bonilla et al., 2003) leaves. Main phenolic compounds were also analyzed in V. labrusca leaves (Dani et al., 2010; Dresch et al., 2014). Chen et al. (2018) reviewed V. amurensis polyphenolic composition and related pharmacological properties. At present, the scientific interest about Vitis sp. polyphenolic composition is at least dual: to investigate the health beneficial effects of grapevine leaves as a possible source of natural bioactive compounds, that can be used in nutraceutical and pharmaceutical applications, and to deepen knowledge about their involvement in grapevine defense mechanisms. Different Vitis species might display different metabolic pathways and/or different gene regulations, resulting in the production of specific classes of bioactive polyphenols, or of individual molecules. Knowledge about these subjects could contribute to shed light on the identification of species-related molecules involved in the plant-defense mechanisms, to the chemotaxonomy of the genus Vitis and to the possible identification of specific molecules to use in specific plant-based preparation for nutraceutical, cosmetical, nutritional purposes.

The aim of the present study was to identify the main constitutive polyphenolic compounds in the leaves of seven Vitis species and of one interspecific cross (the rootstock Börner, V. riparia $x V$. cinerea; Figure 1). To the best to our knowledge V. candicans, V. coignetiae, V. v. sylvestris and Börner main leaf constitutive polyphenols were never described. Leaf blades and veins were analysed separately to spread light on polyphenol strategic localization in leaf tissues, to contribute to explain the grapevinepathogen interaction in specific biological systems. 


\section{MATERIALS AND METHODS}

2.1 Plant Material. Four American (V. candicans, V. riparia, V. berlandieri and Börner), two Asian (V.amurensis, V. coignetiae) and one Eurasian (V.v. sylvestris) grapevine genotypes were studied (Table 1; Figure 1). All the studied accessions were previously checked for their trueness to type by morphology and molecular markers. The studied Vitis genotype leaves were collected in the collection vineyard of DISAFA, University of Turin, Grugliasco (Piedmont, Italy), sampled five times during the season: $1=28^{\text {th }}$ of May (148 day of the year - DOY), $2=22^{\text {nd }}$ of June (DOY 173), $3=14^{\text {th }}$ of July (DOY 195), $4=3^{\text {rd }}$ of August (DOY 215), $5=28^{\text {th }}$ of August (DOY 214), in 2015. The collection vineyard was managed routinely during spring and summer as already described (Kedrina-Okutan et al., 2018) (Kedrina-Okutan et al., 2018). One field parcel was generally constituted by four consecutive plants used to collect the leaves; leaves were detached between the fourth and seventh node of the main shoots from the west side of the row. Pools of 15 adult and healthy leaves (visual evaluation) were collected at each sampling time and divided into three replicates. After sampling, leaves were immediately transported to the laboratory for further analyses.

2.2 Reference Compounds and Reagents. Orientin, isoorientin, astilbin and caftaric acid were purchased from Sigma-Aldrich S.r.l. (Milan, Italy). Vitexin, trans-fertaric acid and trans-coutaric acid were purchased from Phytolab (Vestenbergsgreuth, Germany). (+)-catechin, (-)-epicatechin, (-)epicatechin gallate, (-)-epigallocatechin gallate, proanthocyanidin $\mathrm{B}_{1}$, proanthocyanidin $\mathrm{B}_{2}$, quercetin 3$O$-glucoside, quercetin 3-O-glucuronide, kaempferol 3-O-glucoside, kaempferol 3-O-glucuronide, myricetin 3-O-glucoside and isorhamnetin 3-O-glucoside from Extrasynthèse (Genay, France). Folin-Ciocalteu reagent and tartaric acid were purchased from Merck (Darmstadt, Germany); sodium sulfate and sodium metabisulfite were purchased from BDH Laboratory Supplies (Poole, England).

2.3 Measurement of Dry Matter. Leaf tissue dry matter was measured three times during the season at DOY 186, DOY 200 and DOY 241. Leaf veins and blades were separated and dried inside an oven for 72 hours at constant temperature of $110^{\circ} \mathrm{C}$. The weight differences after exsiccation were measured, and results were expressed as percentage of dry weight over fresh weight. 
sub-samples of five, and veins and blades were immediately separated. Two grams of tissue were randomly chosen form the three sub-samples and extracted in a hydroalcoholic buffer $(\mathrm{pH}=3.9,40 \%$ ethanol, $22 \mathrm{~mL} \mathrm{~L}^{-1}$ of $1 \mathrm{~N} \mathrm{NaOH}, 5 \mathrm{~g} \mathrm{~L}^{-1}$ of tartaric acid, $2 \mathrm{~g} \mathrm{~L}^{-1}$ of sodium metabisulfite). For sample homogenization and polyphenol extraction, an Ultraturrax dispersing machine (IKA, Staufen, Germany) was used for around $1 \mathrm{~min}$ setting the speed at $10000 \mathrm{rpm}$ followed by $10 \mathrm{~min}$ of centrifugation at 4000 rpm. The supernatant was separated, and the pellet was resuspended with the same buffer; the resuspension was kept in the dark for $30 \mathrm{~min}$ and then centrifuged again. The two supernatants were combined and brought to a final volume of $50 \mathrm{~mL}$. Obtained leaf extracts were stored at $-20{ }^{\circ} \mathrm{C}$ until further analysis.

2.5 Measurement of Total Polyphenols. The method of Singleton et al. (1999) was used and results were expressed as gram of (+)-catechin equivalents (CE) per kg of blades/veins dry weight (DW).

Briefly, $100 \mu \mathrm{L}$ of leaf extract were mixed with $5 \mathrm{~mL}$ ultrapure water and $1 \mathrm{~mL}$ of Folin-Ciocalteu $\mathrm{Na}_{2} \mathrm{CO}_{3}$ and ultrapure water were added until final volume of $20 \mathrm{~mL}$. The mixture was incubated in the dark for $90 \mathrm{~min}$ and the absorbance was read at $760 \mathrm{~nm}$ by UV/Vis spectrophotometer (PerkinElmer, Lambda 25, Beaconsfield, Bucks, UK).

\subsection{Analysis of individual polyphenols.}

2.6.1 Sample preparation. Prior to the chromatographic analysis, the extracts were diluted with $1 \mathrm{M}$ phosphoric acid 90/10 v/v and passed through $0.20 \mu \mathrm{m}$ membrane filter GHP Acrodisc (PALL Italia, Buccinasco, Milan, Italy) (Di Stefano and Cravero, 1992).

Individual phenolic compound analysis by HPLC-ESI-MS/MS. Chromatographic separation was performed by HPLC-DAD system (HPLC 1100, Agilent Technologies, U.S.) equipped with column Luna C-18 150 x 2 mm (Phenomex Aschaffenburg, Germany). Mobile phase solvent A was water with formic acid $0.1 \%$ and solvent $\mathrm{B}$ was methanol with formic acid $0.1 \%$; the gradient program for solvent B was the following: 0-30 min 0-50 \% B; 30-35 min 50-100 \% B; 35-50 min $100 \% \mathrm{~B}$ and back to initial 
conditions from 50 to $55 \mathrm{~min}$, followed by $10 \mathrm{~min}$ of isocratic flow. Injection volume was $5 \mu \mathrm{L}$, flow rate $200 \mu \mathrm{L} \mathrm{min}{ }^{-1}$ and individual phenolic compounds were detected at 280, 320, and $370 \mathrm{~nm}$. For the mass spectrometry analyses, a Bruker Daltonics esquire $3000^{\text {plus }}$ ion trap spectrometer (Bruker Daltonics, HB, Germany) equipped with electrospray (ESI) was used, operating at positive and negative modes. The scan mode was between $100-800 \mathrm{~m} / \mathrm{z}$, with a scan resolution of $13000 \mathrm{~m} / \mathrm{z} / \mathrm{s}$ until the ICC target reached either 20000 or maximum accumulation time of $200 \mathrm{~ms}$. The MS instrument operated with nitrogen as drying gas at a temperature of $330{ }^{\circ} \mathrm{C}$ (flow rate of $9 \mathrm{~L} \mathrm{~min}^{-1}$ ). Ionization voltage of the electrospray capillary source was $4000 \mathrm{~V}$ and tandem MS was carried out using helium as the collision gas $\left(4.21 \times 10^{-6}\right.$ mbar) with $1 \mathrm{~V}$ collision voltage. MS identification of metabolites was according to mass spectra, product ion spectra, retention time and confirmed with authentic standards and published data.

2.6.2 Individual phenolic compound quantification by HPLC-DAD. The quantification of phenolic compounds was performed by HPLC-DAD according to previously published methods (Di Stefano and Cravero, 1992; Ferrandino and Guidoni, 2010). Stationary phase column was Licrosphere $100 \mathrm{RP5} \mu \mathrm{m})$ packed into LiChroCART 250-4 $(25 \times 0.4 \mathrm{~cm}$ ID) HPLC-Cartridge (Merck KGaA, Germany) with guard column (LiChroCART 4-4). Mobile phase solvent A was phosphoric acid $10^{-3} \mathrm{M}$ and solvent $\mathrm{B}$ was pure methanol. Run time was $50 \mathrm{~min}$, temperature $25^{\circ} \mathrm{C}$ and DAD peaks were detected at $280 \mathrm{~nm}, 320 \mathrm{~nm}$ and $360 \mathrm{~nm}$. Compounds were identified based on compliance with data obtained from available pure standards and quantified based on standard curve constructed per each individual molecule. Among flavanonol, as exclusively dihydroquercetin-rhamnoside (astilbin) was available as commercial standard, semi-quantification of individual compounds was carried out using the astilbin standard curve. The average flavonol profile of individual genotype was calculated averaging results of five sampling dates.

\subsection{Statistical analysis.}

All data are averages of three biological replicates and standard errors. The analysis of variance was performed by one-way ANOVA with IBM SPSS Statistics software program version 24.0 for Windows 
193 (SPSS Inc., Chicago, IL). In case of significant differences $(\mathrm{P} \leq 0.05)$, means were compared by Tukey-

194 b post-hoc test. Results related to leaf blade and vein polyphenolic composition taken separately were 195 used to run a series of principal component analysis (PCA); correlated variables were progressively 196 excluded, when this correlation had a biological meaning. Species and dates of sampling were separated 197 on the basis of specific classes of polyphenols (i.e. variables). PCA analysis was performed by SAS 9.4 198 for Windows (SAS Institute Inc., Cary, NC, US).

199

200 Table 1. Origin and botanical sub-generic series of the studied genotypes.

\begin{tabular}{llll}
\hline Plant name & Abbreviation & Origin & Series $^{a}$ \\
Vitis candicans & CAN & American & Candicansae \\
Vitis riparia $\mathrm{cv}$ Gloire de Montpellier & RIP & American & Ripariae \\
Vitis rupestris cv du Lot & RUP & American & Ripariae \\
Vitis berlandieri & BER & American & Cinereae \\
Börner $($ V. riparia x V. cinerea) & BOR & American & Ripariae X Cinereae \\
Vitis coignetiae & COI & Asian & Lambruscae \\
Vitis amurensis & AMU & Asian & Flexuosae \\
Vitis vinifera subsp. sylvestris & SYL & Eurasian & Viniferae \\
\hline
\end{tabular}




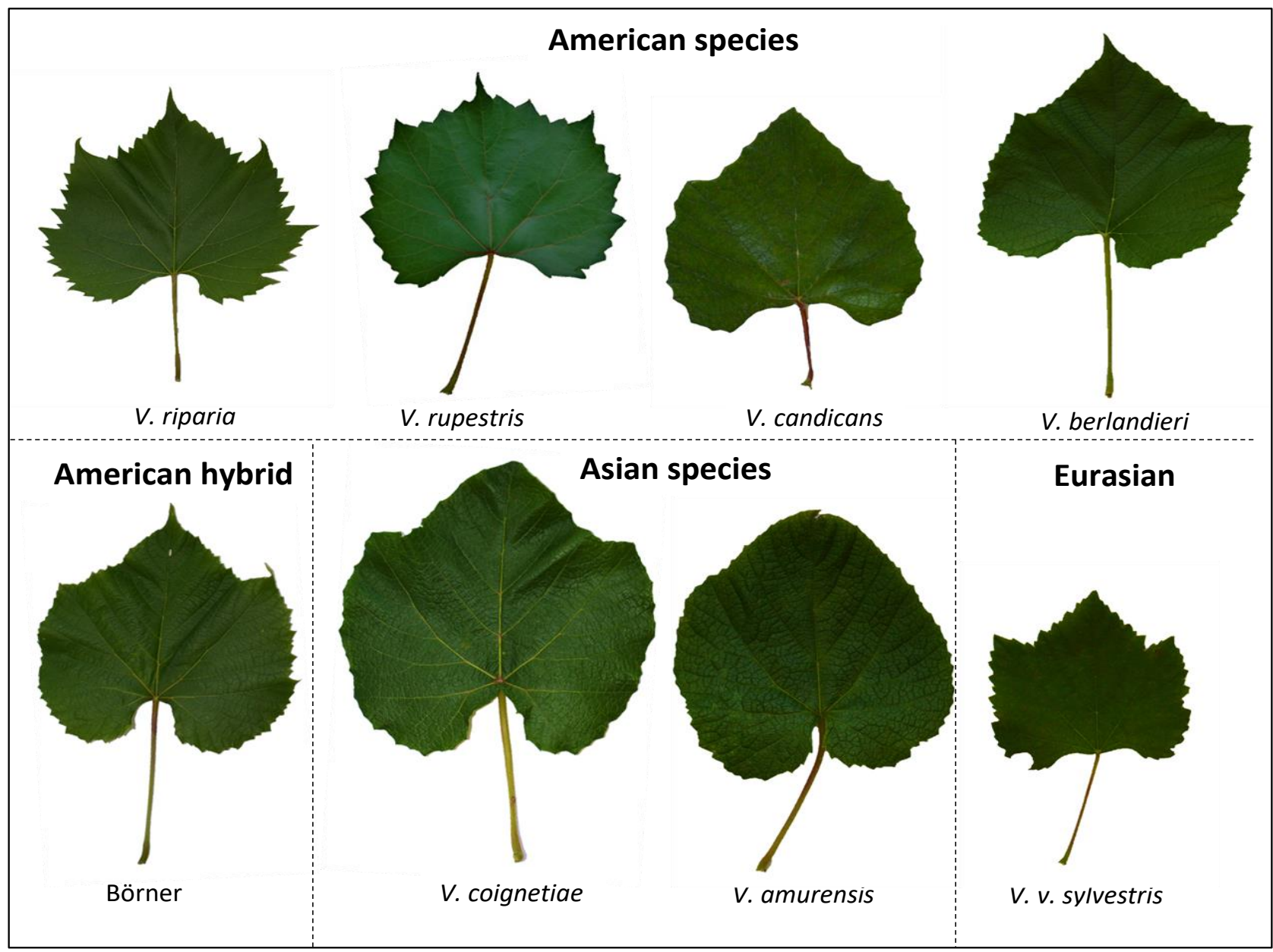

Figure 1. Leaves of eight Vitis genotypes.

\section{RESULTS}

Significant differences of water content occurred among Vitis species at the same picking time (Table 2); however, differences did not exceed $7 \%$ in blades and $8 \%$ in veins. Within the species, water content evolution during the vegetative season was not higher than $6 \%$; in blades of $V$. candicans, $V . v$. sylvestris, Börner and $V$. coignetiae dry matter (DM) content changes during the season were never significant. The comparison between averages of all analyzed grapevine blades and veins showed that dry matter content in veins was around $10 \%$ lower than in blades. Concentrations of compounds were calculated and expressed as amounts per dry matter, even though leaf extracts were prepared from fresh leaves: this choice was done to minimize the well detailed polyphenol analysis perturbations due to losses or to chemical alterations during preparation (Abascal et al., 2005). 
Table 2. Dry matter (\%) in leaves of Vitis genotypes during the vegetative season ${ }^{a}$

\begin{tabular}{|c|c|c|c|c|c|c|c|}
\hline & \multicolumn{2}{|l|}{ DOY 186} & \multicolumn{2}{|l|}{ DOY 200} & \multicolumn{2}{|l|}{ DOY 241} & date \\
\hline & & $\#$ & Blades & $\#$ & & \# & Sampling dates \\
\hline AMU & $32.09 \pm 0.03 \mathrm{a}$ & $\mathrm{e}$ & $34.43 \pm 0.58 b$ & $\mathrm{c}$ & $35.29 \pm 0.23 b$ & $\mathrm{bc}$ & $*$ \\
\hline CAN & $29.71 \pm 0.30$ & cde & $29.68 \pm 0.18$ & $\mathrm{ab}$ & $28.94 \pm 1.63$ & $\mathrm{a}$ & $\mathrm{ns}$ \\
\hline RIP & $27.78 \pm 0.69 a$ & $a b$ & $28.05 \pm 0.79 a$ & $\mathrm{a}$ & $31.95 \pm 1.21 b$ & $\mathrm{ab}$ & $*$ \\
\hline RUP & $27.35 \pm 0.75 a$ & $\mathrm{a}$ & $27.16 \pm 0.80 a$ & $\mathrm{a}$ & $33.51 \pm 1.01 b$ & $\mathrm{~b}$ & $* *$ \\
\hline BER & $31.45 \pm 0.18 \mathrm{a}$ & de & $31.86 \pm 1.07 \mathrm{a}$ & $\mathrm{bc}$ & $37.57 \pm 0.61 b$ & $\mathrm{c}$ & $* *$ \\
\hline COI & $29.59 \pm 0.43 a$ & $\mathrm{bc}$ & $32.09 \pm 0.70 b$ & $\mathrm{bc}$ & $32.93 \pm 0.53 b$ & $a b$ & $*$ \\
\hline SYL & $31.39 \pm 0.62$ & de & $29.70 \pm 0.83$ & $a b$ & $31.76 \pm 0.61$ & $\mathrm{ab}$ & $\mathrm{ns}$ \\
\hline BOR & $30.57 \pm 0.66$ & de & $31.49 \pm 0.74$ & $\mathrm{bc}$ & $32.88 \pm 0.35$ & $a b$ & $\mathrm{~ns}$ \\
\hline average & $29.99 \pm 0.37$ & & $30.56 \pm 0.51$ & & $33.10 \pm 0.56$ & & \\
\hline species & & $* *$ & & $* *$ & & $* *$ & \\
\hline & & & Veins & & & & \\
\hline $\mathrm{AMU}$ & $19.01 \pm 0.42 \mathrm{a}$ & $\mathrm{ab}$ & $22.61 \pm 0.47 b$ & $\mathrm{bc}$ & $22.32 \pm 0.33 b$ & $\mathrm{~b}$ & $* *$ \\
\hline CAN & $23.14 \pm 0.70 b$ & $\mathrm{~b}$ & $23.61 \pm 0.99 b$ & $\mathrm{c}$ & $19.32 \pm 0.60 \mathrm{a}$ & $\mathrm{a}$ & * \\
\hline RIP & $21.21 \pm 0.71 \mathrm{ab}$ & $\mathrm{b}$ & $20.52 \pm 0.52 \mathrm{a}$ & $\mathrm{ab}$ & $22.88 \pm 0.21 b$ & $\mathrm{bc}$ & $*$ \\
\hline RUP & $19.23 \pm 1.43 a$ & $a b$ & $20.02 \pm 0.52 \mathrm{a}$ & $\mathrm{ab}$ & $25.13 \pm 0.34 b$ & $\mathrm{~cd}$ & $* *$ \\
\hline BER & $21.37 \pm 0.40 \mathrm{a}$ & $a b$ & $23.08 \pm 1.12 \mathrm{a}$ & $\mathrm{bc}$ & $26.30 \pm 0.58 b$ & d & $*$ \\
\hline $\mathrm{COI}$ & $17.82 \pm 0.53$ & $\mathrm{a}$ & $18.89 \pm 0.72$ & $\mathrm{a}$ & $19.27 \pm 0.66$ & $\mathrm{a}$ & $\mathrm{ns}$ \\
\hline SYL & $21.22 \pm 0.47 \mathrm{a}$ & $a b$ & $23.74 \pm 0.15 b$ & $\mathrm{c}$ & $27.28 \pm 0.48 c$ & $\mathrm{~d}$ & $* *$ \\
\hline BOR & $20.59 \pm 0.45 a$ & $\mathrm{ab}$ & $20.26 \pm 0.33 a$ & $\mathrm{ab}$ & $23.88 \pm 0.81 b$ & $\mathrm{bc}$ & $* *$ \\
\hline average & $20.45 \pm 0.38$ & & $21.59 \pm 0.42$ & & $23.30 \pm 0.60$ & & \\
\hline species & & * & & $* *$ & & $* *$ & \\
\hline
\end{tabular}

${ }^{a}$ Results are expressed as means \pm standard errors (SE; $n=3$ ). Different small letters in each individual row after averages \pm SE represent statistical differences among sampling dates, within the same species. In columns individuated with \#, different letters represent statistical differences among genotypes, within the same tissue and date. General statistical differences among sampling dates and species were assessed by a post-hoc Tukey-b test for $\mathrm{P} \leq 0.05(*)$, $\mathrm{P} \leq 0.01(* *)$; ns - not significant. Day of the year (DOY) refers to $5^{\text {th }}$ of July (DOY 186); $19^{\text {th }}$ of July (DOY 200); $29^{\text {th }}$ of August (DOY 241 ).

The total polyphenol (TP) content ranged from 60.2 to $165.9 \mathrm{~g} \mathrm{~kg}^{-1} \mathrm{DW}$ in blades and from 28.6 to 130.1 $\mathrm{g} \mathrm{kg}^{-1} \mathrm{DW}$ in veins. V. amurensis blades (Figure 2) displayed higher TP concentration during the entire vegetative season compared to the other genotypes. TP was on average about 1.5 times lower in veins than in blades. TP accumulation trend was different among genotypes: in $V$. riparia, the accumulation trends in veins and blades were similar, whereas in $V$. candicans, TP concentration increased in blades and decreased in veins during the season. 


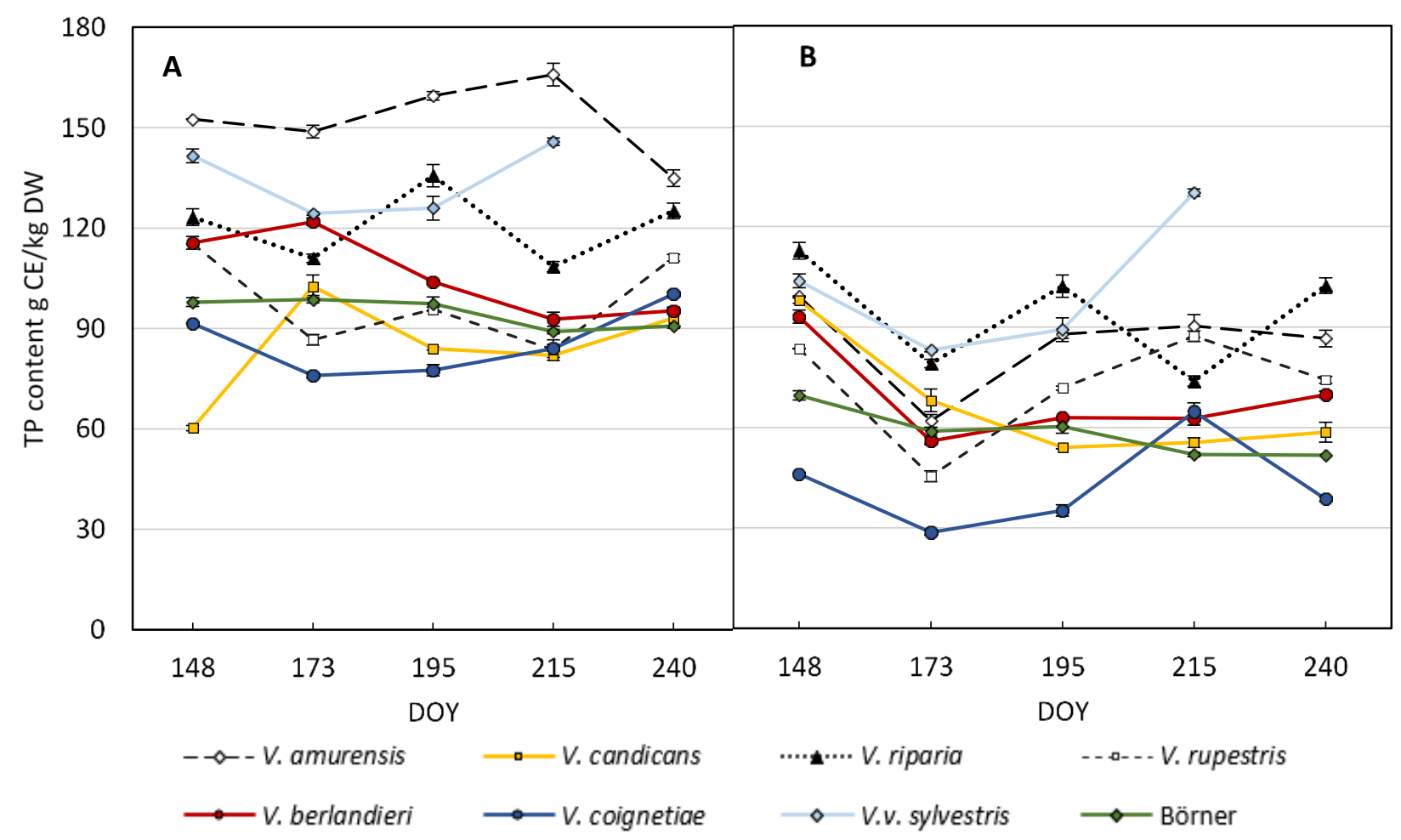

232

3.1 Phenolic Compound Accumulation in Vitis sp. Leaves. Twenty phenolic compounds were identified in the two Asian species, 27 in the four American species and in the hybrid, and 18 in $V . v$. sylvestris. The detected compounds belonged to the groups of flavonols, phenolic acids, flavan-3-ols, proanthocyanidins, flavanonols and flavones. Anthocyanins were exclusively detected in trace amounts or in extremely low concentrations (data not shown) and, in line with what we previously found in varieties of $V$. vinifera sativa (Kedrina-Okutan et al., 2018), in healthy leaves they were found exclusively in veins.

\subsubsection{Flavonols.}

The concentration of flavonol glycosides ranged from 3.6 to $20.6 \mathrm{~g} \mathrm{~kg}^{-1} \mathrm{DW}$ in blades and from 0.8 to $7.7 \mathrm{~g} \mathrm{~kg}^{-1} \mathrm{DW}$ in veins (Figure 3); they were the most abundant phenolic compounds in leaves. We detected a net separation among genotypes based on their ability to accumulate flavonol glycosides during the season. A first group included $V$. amurensis and $V$. riparia, both species displaying the highest 

(Figure 3A). A second group with medium flavonol concentration included $V$. v. sylvestris and $V$. rupestris with a stable concentration trend during the vegetative season. A third group included the remaining species, displaying relatively low total flavonol concentration and slightly decreasing trends during the examined period. Similar results were found in veins: genotypes of the first two groups displayed higher total flavonol concentration and genotypes of the third group lower concentration with decreasing trend during the season (Figure 3B). The comparison between the two compartments within each genotype showed that total flavonol concentration was always higher in blades than in veins. The prevalent flavonol was quercetin 3-O-glucuronide, ranging between $60 \%$ and $92 \%$ of all the detected flavonols (Figure 4; Supplementary Table 1A,B). The most complex flavonol profile was found in $V$. v. sylvestris leaves accumulating seven out of the eight identified flavonol glycosides and trace amount of kaempferol 3-O-glucoside (Figure 4). Kaempferol 3-O-rhamnoside was exclusively found in $V$. $v$. sylvestris that also accumulated significant amounts of quercetin 3-O-rhamnoside. The simplest flavonol profile was found in $V$. amurensis and $V$. candicans that exclusively accumulated quercetin and kaempferol glucuronides and glucosides. In $V$. berlandieri and in Börner, no kaempferol glycosides were detected.

\subsubsection{Phenolic acids.}

Total phenolic acid content in blades ranged from 3.2 to $10.2 \mathrm{~g} \mathrm{~kg}^{-1}$ dry weight and showed different accumulation trends among genotypes. In Asian species, V. amurensis and V. coignetiae, total phenolic acid concentration fell during the vegetative season. In American species, concentration firstly increased and then it started to fall between July and beginning of August (DOY 173-215), whereas in $V$. v. sylvestris, concentration decreased between the first and the second sampling date and then rose from the end of June (DOY 173) to the beginning of August (DOY 215) (Figure 5A). In leaf veins, phenolic acid content showed a significant drop between the first and the second sampling date in all genotypes, followed by a relatively steady period (Figure 5B). Total phenolic acid concentration in veins was lower than in blades in each individual species, except at the first sampling date in $V$. candicans, $V$. 
riparia and $V$. rupestris when concentration in veins was higher than in blades. Hydroxycinnamoyl

274 tartaric acids were the prevalent phenolic acids in leaves, and, based on their characteristic UV maximum

275 absorbance around $320 \mathrm{~nm}$ and mass spectra, they were identified as cis- and trans-forms of caftaric,

276 coutaric and fertaric acid (Table 3). Trans-forms were always prevalent over cis-forms The main

277 phenolic acid in leaves was trans-caftaric acid, which comprised up to $90 \%$ followed by trans-coutaric and trans-fertaric acid (Figure 5C, Supplementary Table 2A, B). On the contrary, in V.rupestris and $V$. riparia trans-fertaric acid displayed higher concentration respect to trans-coutaric acid. Moreover, these two species accumulated an additional molecule, a coutaric acid isomer, that was tentatively identified through its pseudomolecular ion $[\mathrm{M}-\mathrm{H}]^{-}$at $m / z 295$ and two product ions at $m / z, 163,131$ in $\mathrm{MS}^{2}$. Low amounts of protocatechuic acid-glucoside were detected in $V$. rupestris, V. riparia, $V$. amurensis and Börner blades, with a slight increasing trend during the season (Supplementary Table 2A).

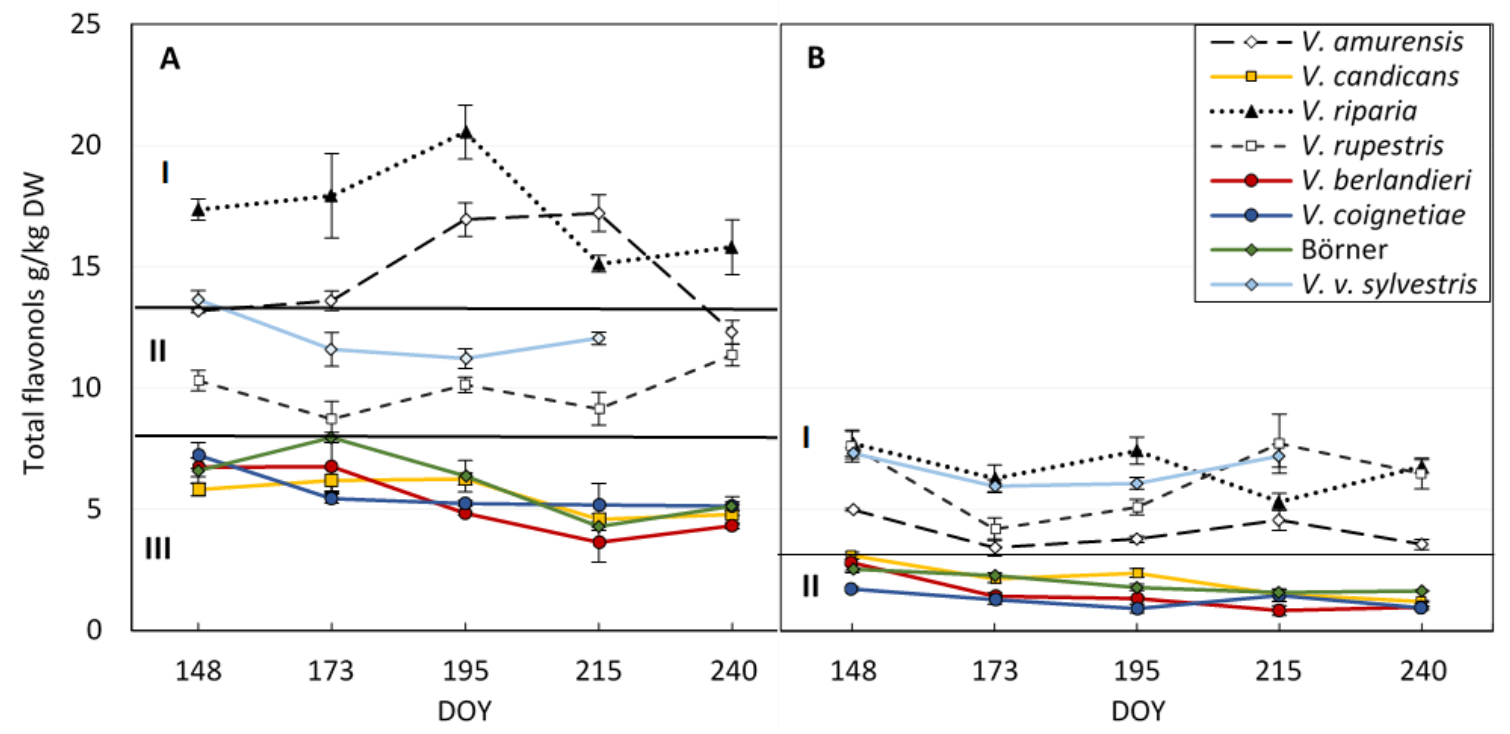

Figure 3. Total flavonol concentration in leaves of eight Vitis genotypes during the vegetative season; 
V. amurensis

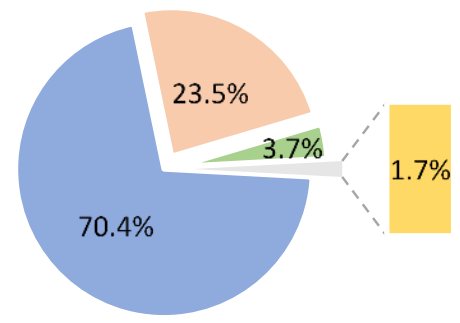

V. riparia

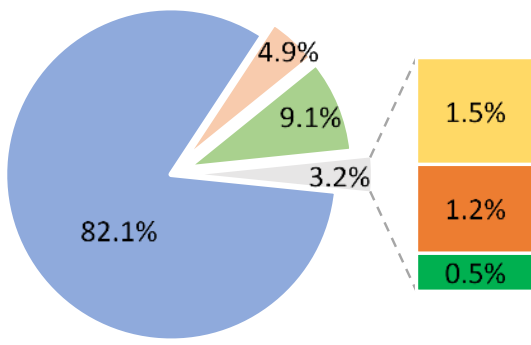

V. berlandieri

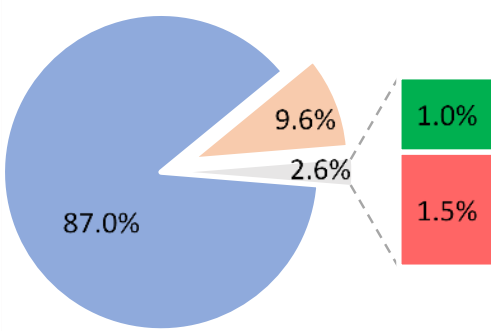

V. candicans

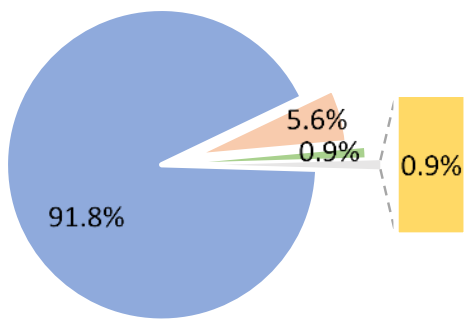

V. rupestris

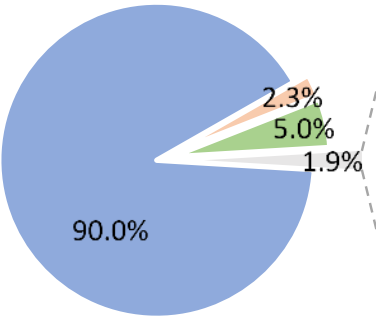

$0.8 \%$

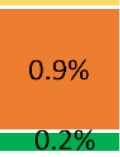

Börner

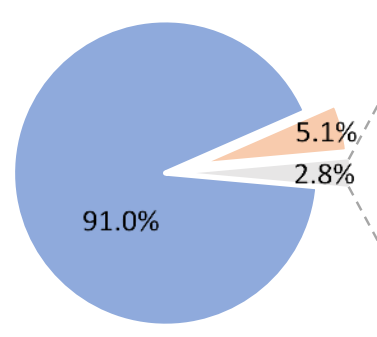

V. coignetiae

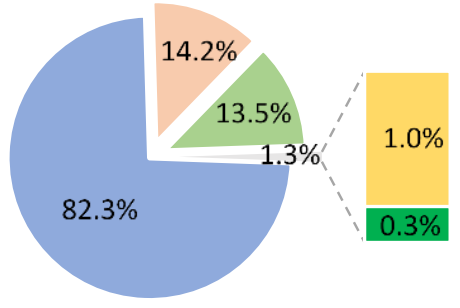

V. v. sylvestris

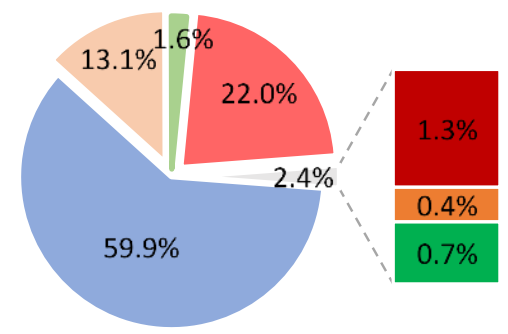

- quercetin 3-O-glucuronide

- quercetin 3-O-glucoside

- kaempferol 3-O-glucuronide

- kaempferol 3-O-rhamnoside

- myricetin 3-O-glucuronide

- myricetin 3-0-glucoside

- quercetin 3-O-rhamnoside

- kaempferol 3-O-glucoside

288 Figure 4. Flavonol profile of leaf blades of eight Vitis genotypes calculated as average of results obtained at five sampling times performed during the vegetative season. 

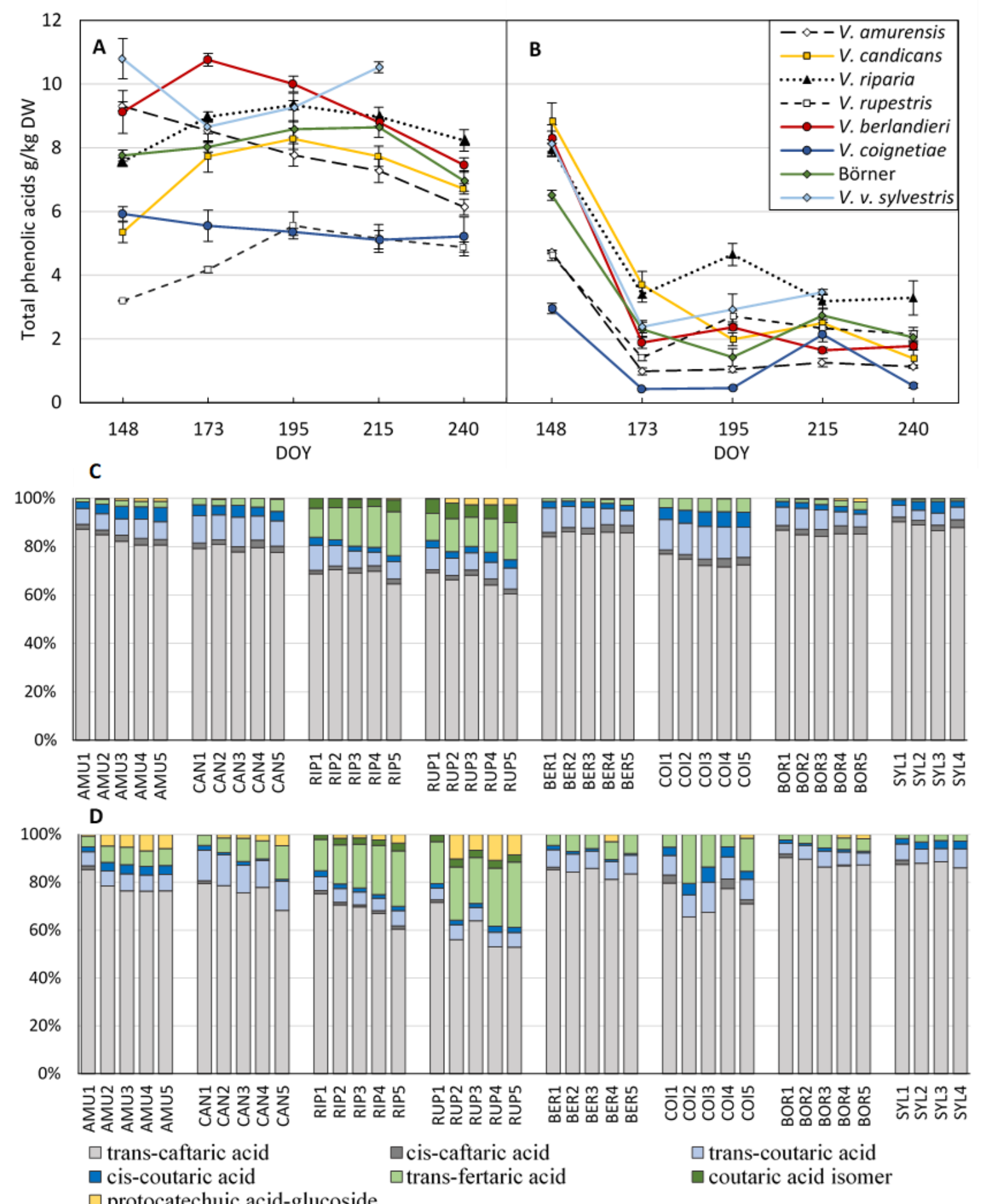

291 Figure 5. Accumulation of phenolic acids in Vitis sp. leaves during the vegetative season. Total phenolic acid concentration in blades (A) and veins (B); results are means of three replicates \pm SE. Phenolic acid profile of leaf blades (C) and veins (D) during the season. For species acronyms see Table 1; numbers after the species acronyms refer to $1=$ DOY 148 ( $28^{\text {th }}$ of May); $2=$ DOY 173 ( $22^{\text {nd }}$ of June $) ; 3=$ DOY 195 ( $14^{\text {th }}$ of July); 4 = DOY 215 ( $3^{\text {rd }}$ of August $)$; and $5=$ DOY $240\left(28^{\text {th }}\right.$ of August $)$. 
Table 3. Phenolic compound identification in leaf blades and veins of eight Vitis genotypes by HPLC-ESI-

\begin{tabular}{|c|c|c|c|c|c|c|}
\hline ID & $\begin{array}{c}\mathrm{Rt} \\
( \pm 0.2 \mathrm{~min})\end{array}$ & $\begin{array}{l}{[\mathrm{M}]^{-}} \\
(\mathrm{m} / \mathrm{z})\end{array}$ & $\begin{array}{c}{\left[\mathrm{MS}^{2}\right]^{-}} \\
(\mathrm{m} / \mathrm{z})\end{array}$ & $\begin{array}{l}{[\mathrm{M}]^{+}} \\
(\mathrm{m} / \mathrm{z})\end{array}$ & $\begin{array}{c}{\left[\mathrm{MS}^{2}\right]^{+}} \\
(\mathrm{m} / \mathrm{z})\end{array}$ & compound identification \\
\hline 1 & 14.5 & 593 & $425,407,289$ & 595 & 291 & (epi)gallocatechin-(epi)catechin \\
\hline 2 & 16.5 & 315 & 153,123 & & & protocatechuic acid-glucoside \\
\hline 3 & 18.3 & 311 & 179 & & & cis-caftaric acid \\
\hline 4 & 18.8 & 577 & $451,407,289$ & & & procyanidin $\mathrm{B}_{3}$ \\
\hline 5 & 19.9 & 311 & 179 & & & trans-caftaric acid \\
\hline 6 & 21.8 & 289 & $245,205,179$ & 291 & $273,165,123$ & catechin \\
\hline 7 & 22.5 & 295 & 163 & & & cis-coutaric acid \\
\hline 8 & 23.0 & 577 & $451,425,407,289$ & 579 & $427,409,289$ & procyanidin $\mathrm{B}_{1}$ \\
\hline 9 & 23.5 & 295 & 163 & & & trans-coutaric acid \\
\hline 10 & 23.8 & 729 & $577,441,289$ & 731 & 579,409 & procyanidin dimer gallate \\
\hline 11 & 24.9 & 595 & $576,385,355$ & & & unknown proanthocyanidin \\
\hline 12 & 25.1 & 325 & 193 & & & trans-fertaric acid \\
\hline 13 & 25.7 & 289 & $245,205,179$ & 291 & $273,165,123$ & epicatechin \\
\hline 14 & 27.7 & 465 & $303,285,151$ & & & dihydroquercetin-hexoside \\
\hline 15 & 27.7 & 295 & 163,131 & & & coutaric acid isomer \\
\hline 16 & 29.2 & 615 & $481,407,359$ & & & unknown \\
\hline 17 & 30.8 & 447 & $393,357,327$ & 449 & $413,383,329$ & luteolin 8-C-glucoside (orientin) \\
\hline 18 & 31.1 & 449 & $287,269,151$ & & & dihydrokaempferol hexoside \\
\hline 19 & 31.4 & 447 & $429,357,327,285$ & 449 & $431,413,383$ & luteolin 6-C-glucoside (isoorientin) \\
\hline 20 & 31.8 & 479 & 317 & 481 & 319 & myricetin 3-O-glucoside \\
\hline 21 & 32.3 & 431 & $341,311,283$ & 433 & $415,367,283$ & apigenin 8 - $C$-glucoside (vitexin) \\
\hline 22 & 32.7 & 493 & 317 & 495 & 319 & myricetin 3-O-glucuronide \\
\hline 23 & 33.7 & 449 & $303,285,151$ & & & dihydroquercetin-rhamnoside (astilbin) \\
\hline 24 & 33.8 & 431 & $413,341,311,283$ & 433 & $415,367,337$ & apigenin 6- $C$-glucoside (isovitexin) \\
\hline 25 & 34.2 & 447 & 285 & 449 & 287 & luteolin-7-O-glucoside (luteoloside) \\
\hline 26 & 35.1 & 463 & 301 & 465 & 303 & quercetin 3-O-glucoside \\
\hline 27 & 35.6 & 477 & 301 & 479 & 303 & quercetin 3-O-glucuronide \\
\hline 28 & 37.1 & 447 & 301 & 449 & 303 & quercetin 3-O-rhamnoside \\
\hline 29 & 37.2 & 447 & 285 & 449 & 287 & kaempferol 3-O-glucoside \\
\hline 30 & 37.5 & 461 & 285 & 463 & 287 & kaempferol 3-O-glucuronide \\
\hline 31 & 38.3 & 431 & 285 & 433 & 287 & kaempferol 3-O-rhamnoside \\
\hline
\end{tabular}

${ }^{a}$ ID numbers correspond to peaks reported in Supplement Figure 1, 2. that prevalently accumulated in blades. Specifically, the concentration of flavan-3-ols ranged from 0.44 to $3.39 \mathrm{~g} \mathrm{~kg}^{-1}$ in blades and from 0.04 to $1.55 \mathrm{~g} \mathrm{~kg}^{-1}$ in veins (Figure 6A and B). In V. amurensis blades, the concentration of total flavan-3-ols was significantly higher respect to the other genotypes, and it 
displayed a decreasing trend, so that at the end of the examined period the differences respect to the other genotypes were less marked. In $V$. rupestris flavan-3-ol concentration increased almost continuously during the entire vegetative season, oppositely to the other analyzed genotypes. The flavan3-ol profile analysis showed that (+)-catechin was generally the prevalent flavan-3-ol, corresponding up to $73 \%$ of total flavan-3-ols in blades (Figure 5C; Supplementary Table 3A) or the exclusive one in $V$. coignetiae veins (Figure 5D; Supplementary Table 3B). In the Asian species V. amurensis, (-)epicatechin was the prevalent flavan-3-ol in blades, similarly to V.v. sylvestris and $V$. rupestris veins from the second sampling date onwards. Concentration of (-)-epigallocatechin showed an increasing trend during the examined season and in blades it accounted up to $38 \%$ by the end of the season. Interestingly, in veins of $V$. coignetiae and Börner, (-)-epicatechin was absent during the whole season, and in $V$. candicans it was exclusively detected at the first sampling date. The relative abundance of ()-epicatechin gallate ranged between $4.7 \%$ and $14.9 \%$ and it was exclusively found in blades of $V$. rupestris, V. berlandieri and Börner.

\subsubsection{Proanthocyanidins.}

Proanthocyanidin concentration ranged from 0.21 to $3.09 \mathrm{~g} \mathrm{~kg}^{-1}$ in blades. Particularly high concentration was detected in $V$. amurensis at first four sampling dates and in V. berlandieri at first two sampling dates, followed by a sharp concentration fall (Figure 7A). In veins, PA exclusively accumulated in $V$. amurensis and $V$. candicans during the whole season and in some dates in four species, also in $V$. coignetiae and $V . v$. sylvestris. PA content was generally higher in blades than in veins, with the only exception of $V$. amurensis and $V$. candicans at DOY 148 (end of May) when vein PA content was higher respect to that of blades (Figure 7; Supplementary Table 4A,B). Procyanidin B accumulated both in blades and veins. Additionally, in V. amurensis, V. berlandieri and in Börner blades and in $V$. amurensis veins, a procyanidin dimer gallate was tentatively identified by pseudomolecular ion $[\mathrm{M}-\mathrm{H}]^{-}$at $\mathrm{m} / \mathrm{z}$ 729; product ions at $\mathrm{m} / \mathrm{z} 577,441,289$ in $\mathrm{MS}^{2}$ and characteristic UV maximum absorbance at $280 \mathrm{~nm}$, in line with other report (Flamini, 2013). In V. berlandieri and Börner blades, 
procyanidin dimer gallate accounted for around $50 \%$ of total PA, whereas in $V$. amurensis, it accounted for $20-25 \%$ of total PA during the vegetative season.

335 in blades (pseudomolecular ion $[\mathrm{M}-\mathrm{H}]^{-}$at $\mathrm{m} / \mathrm{z}, 593$; product ions at $\mathrm{m} / \mathrm{z}, 425,407,289$ in $\mathrm{MS}^{2}$; Table 3),

336 In addition, in $V$. amurensis blades, another B-type of procyanidin was identified, most likely

337 procyanidin $\mathrm{B}_{3}$ and one further proanthocyanidin that remains unknown (Table 3). 

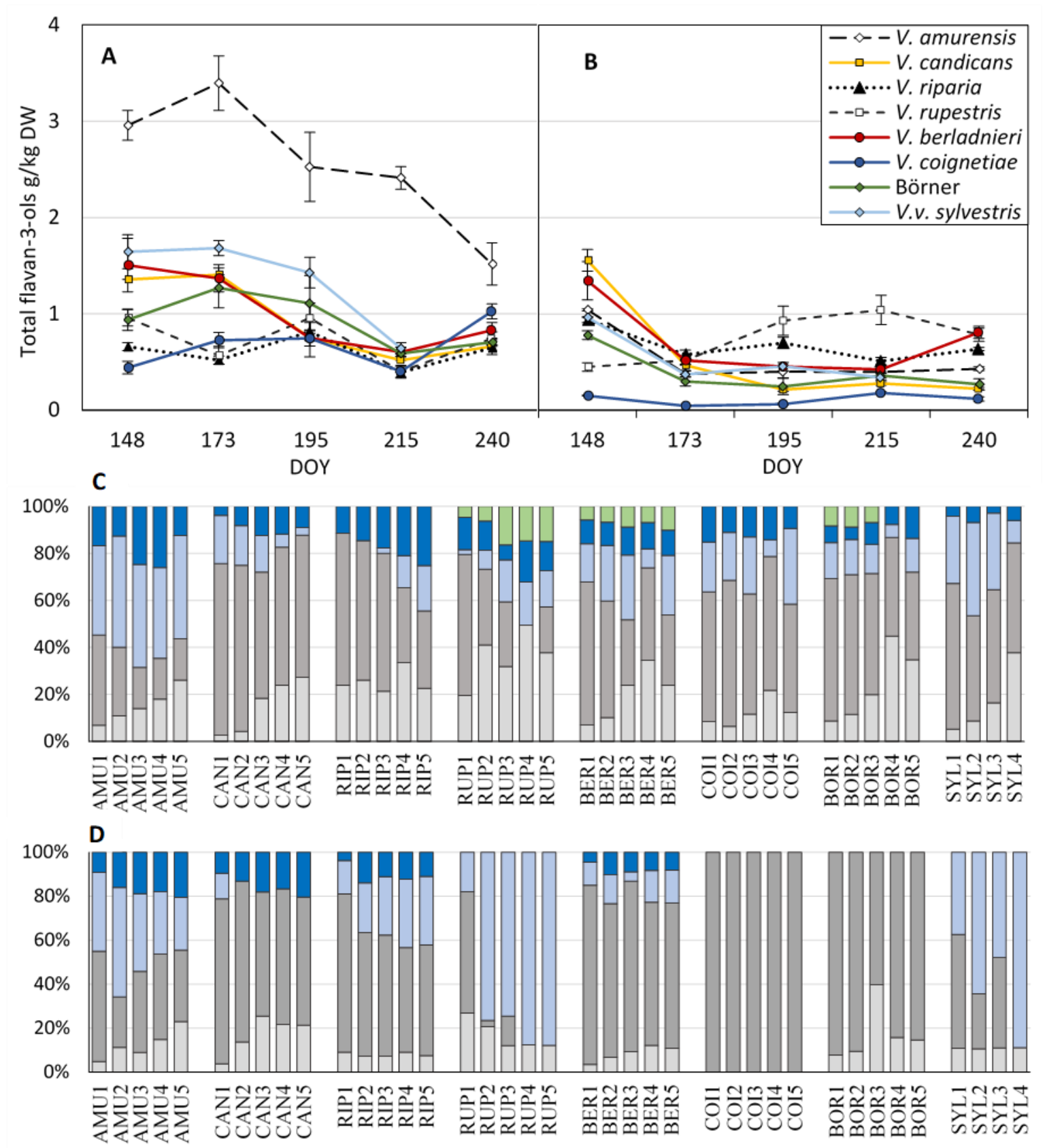

$\square(-)$-epigallocatechin $\square(+)$-catechin $\square(-)$-epicatechin $\square(-)$-epigallocatechin gallate $\square(-)$-epicatechin gallate

340 Figure 6. Accumulation of flavan-3-ols in Vitis sp. leaves during the vegetative season. Total flavan-3341 ol concentration in blades (A) and veins (B); results are means of three replicates \pm SE. Flavan-3-ol 342 profile of leaf blades (C) and veins (D) during the season; see Figure 5 for genotype acronym specification. 

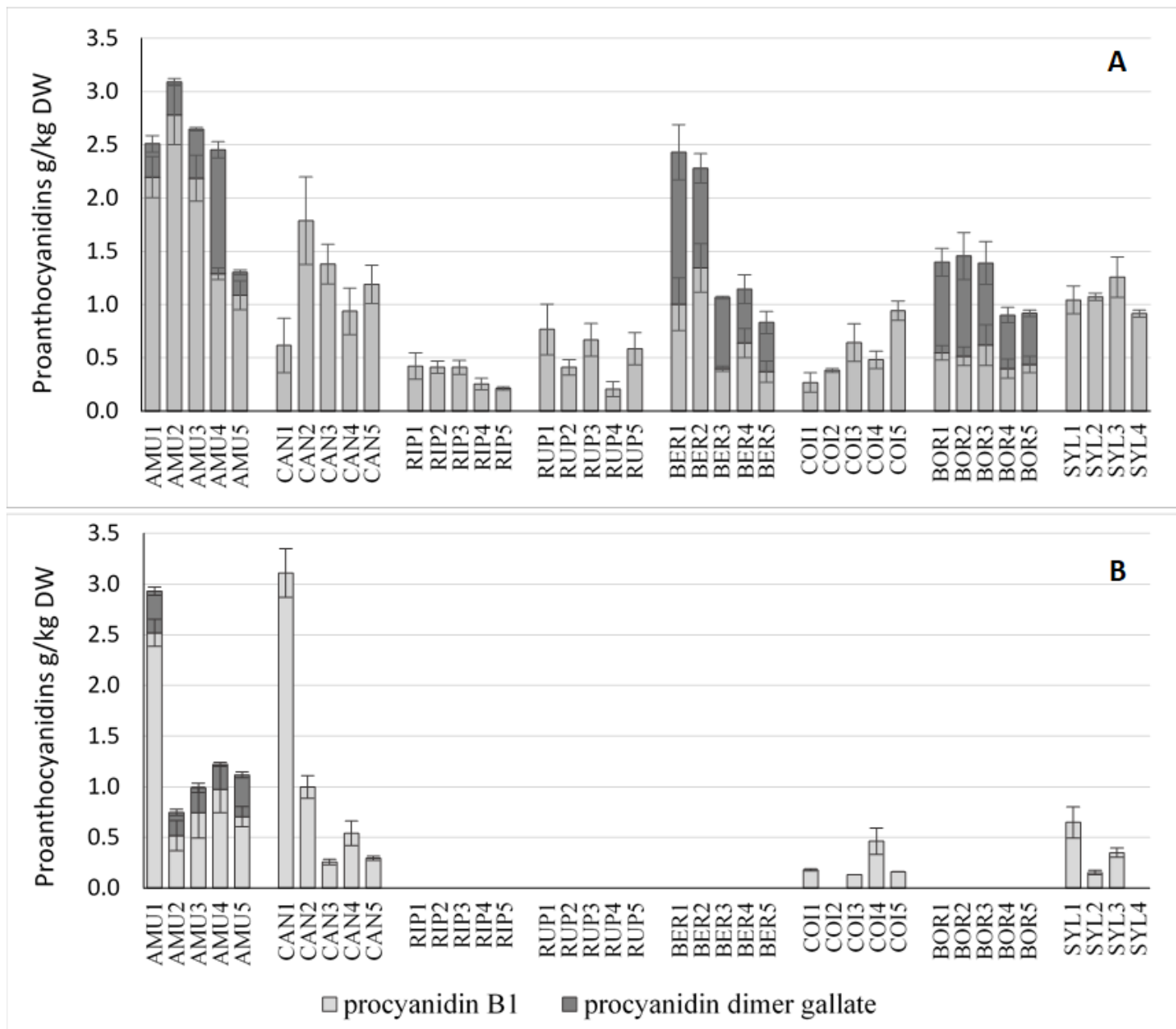

Figure 7. Accumulation of proanthocyanidin in Vitis sp. leaves $(\mathrm{A}=$ blades; $\mathrm{B}=$ veins $)$ during the vegetative season. Means of three replicates \pm SE; see Figure 5 for genotype acronym specification.

\subsubsection{Flavanonols.}

In blades, flavanonols were detected exclusively in $V$. amurensis and $V$. coignetiae, whereas in

veins, they were also found in V. v. sylvestris. (Figure 8; Supplementary Table 4A, B). In blades, concentration was much lower than in veins. Particularly high concentration was found in $V$. amurensis veins with values ranging between 0.95 and $2.12 \mathrm{~g} \mathrm{~kg}^{-1}$ (Figure $8 \mathrm{~B}$ ). In both Asian species, vein total flavanonol concentration showed two peaks, the first at DOY 148 and the second at DOY 215 whereas in $V$. v. sylvestris no differences among sampling times were noticed. Three flavanonol glycosides were quantified and identified in leaves by the characteristic absorbance maximum at $290 \mathrm{~nm}$ and correspondent mass spectra (Table 3): dihydroquercetin-hexoside was the main flavanonol found in $V$. 
amurensis and $V$. coignetiae where it was the exclusive flavanonol in blades and it accounted for up to $90 \%$ of total flavanonols in veins (Figure 8A,B). In addition, dihydrokaempferol-hexoside was detected in $V$. amurensis and in $V$. coignetiae veins with no differences among sampling dates. Astilbin (dihydroquercetin-rhamnoside) was exclusively detected in the Eurasian species $V$. v. sylvestris veins.
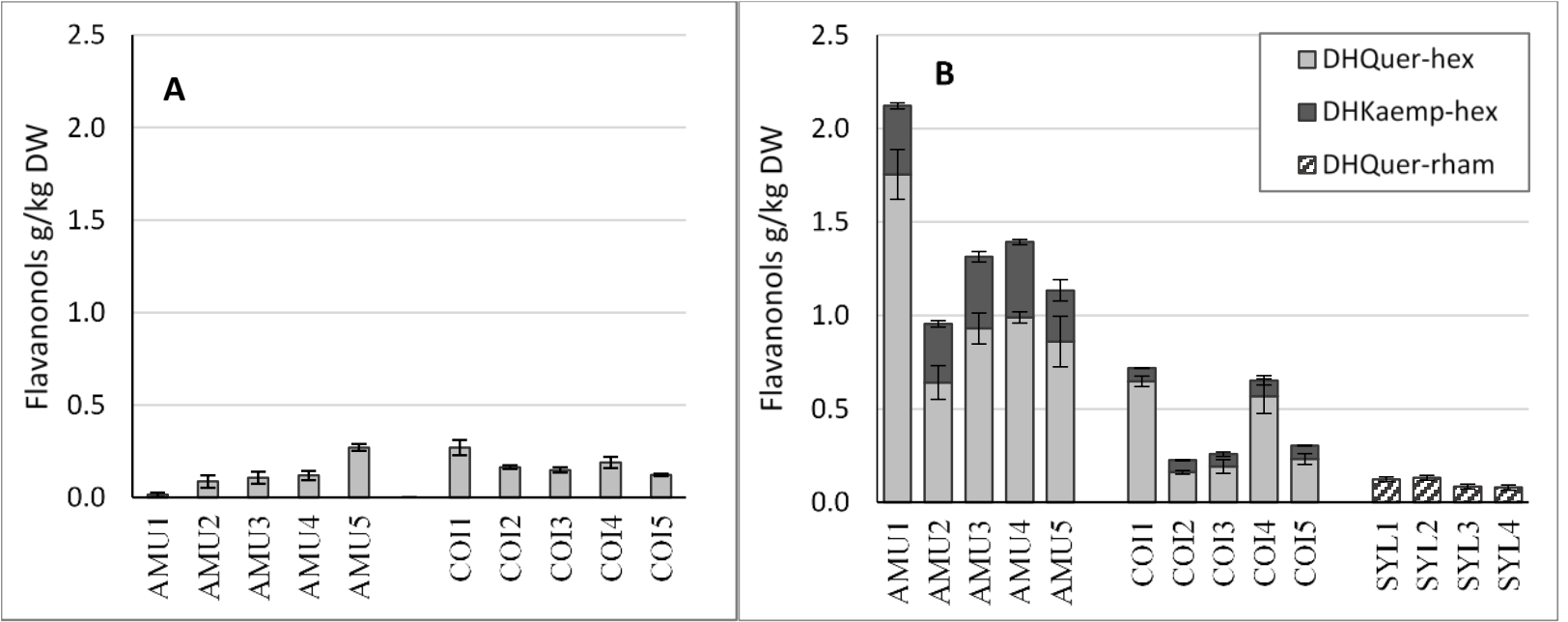

Figure 8. Accumulation of flavanonol content in Vitis sp. leaves $(\mathrm{A}=$ blades; $\mathrm{B}=$ veins $)$ during the vegetative season. Means of three replicates \pm SE; DHQuer - dihydroquercetin; DHKaemp dihydrokaempferol; hex - hexoside; rham - rhamnoside; see Figure 5 for genotype acronym specification.

\subsubsection{Flavones}

Flavones have rarely been detected in leaves and other vegetative organs of grapevine. In fact, also in our analyzed genotypes, flavones accumulated exclusively in $V$. berlandieri and Börner. Total flavone concentration ranged between 2.5 and $4.9 \mathrm{~g} \mathrm{~kg}^{-1} \mathrm{DW}$ in blades (Figure 9A). In comparison with $V$. berlandieri, Börner blades accumulated significantly higher concentration of total flavones from DOY 148 (end of May) until DOY 195 (mid-July). Similar to the other classes of measured polyphenols, flavone concentration was lower in veins respect to blades, ranging from 0.7 to $1.2 \mathrm{~g} \mathrm{~kg}^{-1} \mathrm{DW}$ (Figure 9B). Five flavones accumulated in both tissues, two were apigenin glycosides and three luteolin glycosides. Isomers of apigenin glucosides were differentiated by pseudomolecular ion $[\mathrm{M}-\mathrm{H}]^{-}$at $m / z$ 
and their intensities provided insight into individual compound structure. Apigenin 8-C-glucoside 379 (isovitexin) product ions were detected at $\mathrm{m} / \mathrm{z}$ 283, 311, 341 and apigenin 6 - $C$-glucoside (vitexin) product ions were detected at $m / z 283,311,341,413$ (Table 3). The absence of product ion $\mathrm{m} / \mathrm{z} 413$ and the lower intensity of product ion at $m / z 341\left[{ }^{0,3} \mathrm{X}_{0}-\mathrm{H}\right]^{-}$helped to differentiate apigenin 8 - $C$-glucoside from apigenin 6-C-glucoside, accordingly to Kim et al. (2018). Isomers of luteolin glucoside had pseudomolecular ion $[\mathrm{M}-\mathrm{H}]^{-}$at $\mathrm{m} / z, 447$ and absorbance maximum at 269, $350 \mathrm{~nm}$. Furthermore, comparison of product ion pattern of three luteolin glucoside isomers let us tentatively identify luteolin

(Table 3). The compound with absence of product ion at $\mathrm{m} / \mathrm{z} 429$ and high intensity of product ion at $m / z 357\left[{ }^{0,3} \mathrm{X}_{0}-\mathrm{H}\right]^{-}$was tentatively identified as luteolin 6- $C$-glucoside. Luteolin glucoside isomer with product ion pattern of two high abundance fragment at m/z $285[\mathrm{M}-\mathrm{H}-162]^{-}$and $\mathrm{m} / \mathrm{z} 284[\mathrm{M}-\mathrm{H}-$ $162]^{-\bullet}$ was tentatively identified as luteolin 7-O-glucoside, according to Li et al. (2016). Leaf flavone profile analysis showed that isoorientin together with isovitexin comprised up to $70 \%$ of all detected flavones, thus 8-C was the predominant glycosylation site of flavone aglycones in Vitis sp. leaves (Figure 9; Supplementary Table 5).
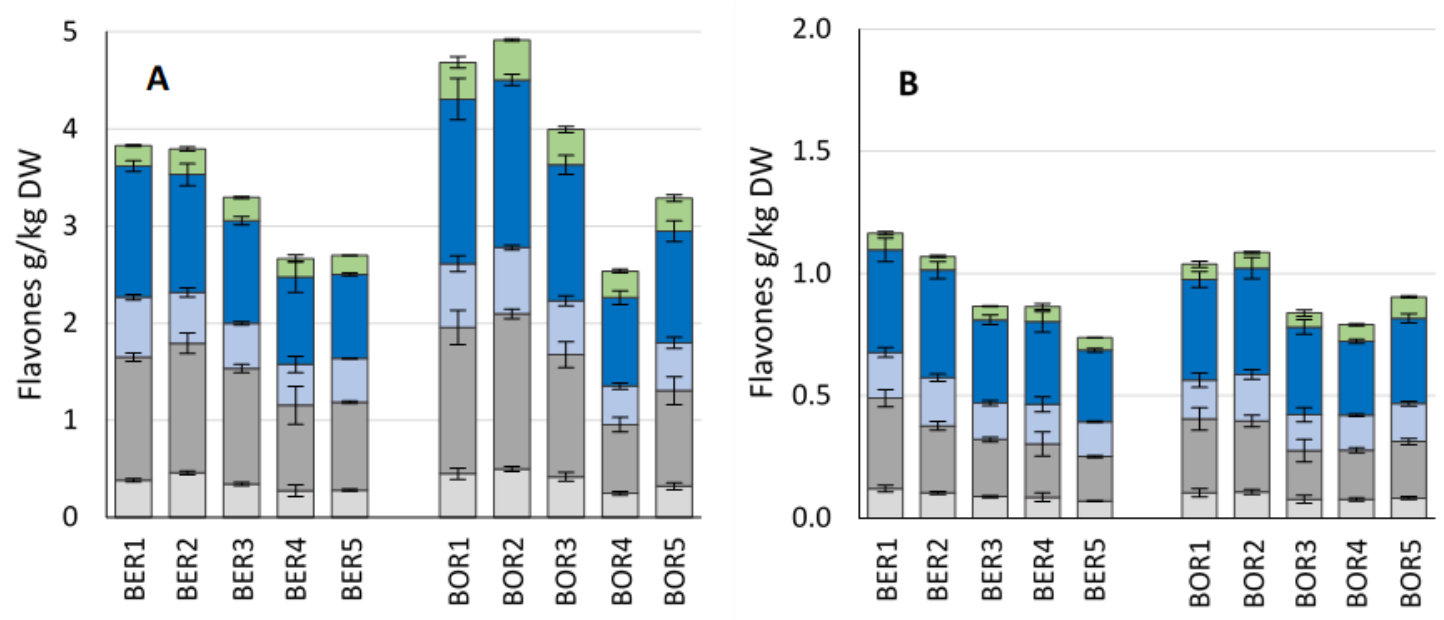

Figure 9. Accumulation of flavones in Vitis sp. leaves ( $\mathrm{A}=$ blades; $\mathrm{B}=$ veins $)$ during the vegetative season. Means of three replicates \pm SE; see Figure 5 for genotype acronym specification. 


\subsection{Overall polyphenolic patterns and genotype associations}

In blades, the PCA model that explained the highest variance with three PRINs (72\%), allowing a net separation of genotypes, based on eleven variables (Table 4) that were gradually chosen to exclude redundancy. Variables associated to the first PRIN were phenolic acids (the sum of fertaric acid, coutaric acid isomer and the cis and trans forms of caftaric acid) and the total concentration of dimeric proanthocyanidins. Genotypes separated on the second PRIN on the basis of myricetin glycoside (glucoside + glucuronide) concentration and of flavonol total amount. The third PRIN separated genotypes based on total flavan-3-ol concentration, evidencing in particular, V. amurensis. Considering that the eigenvalue on PRIN3 was almost 2.0 (1.79, Table 4), the flavone total concentration could be considered as the second variable associated (negatively) to the third PRIN. On this basis, Börner and V. berlandieri, highly associated to the third PRIN negative values, evidenced their peculiar capability to accumulate high amounts of flavones in leaf blades (Figure 9; Figure 10).

In veins, the proposed PCA model (Table 5; Figure 11) explained the $75 \%$ of total variance with the first three PRINs. Variables associated to the first PRIN were total polyphenols, total flavan-3-ols and flavonol glucuronic derivatives; these variables did not markedly identify varieties or specific timepoints of the leaf vegetative cycle, with the only exception of $V$. amurensis, generally associated to positive values of the first PRIN. Flavanonols and glucosides of flavonols were negatively associated to the second PRIN. Dimeric proanthocyanidins associated to the third PRIN, allowed to evidence that in genotypes accumulating this class of compounds, concentration was higher at the first sampling (particularly in V. amurensis, V. candicans, V. berlandieri and in Börner).

\subsection{Seasonal polyphenol-related traits}

The flavonol concentration varied during the vegetative season, but the profile, strictly related to a specific genotype, did not change (Figure 4). 
422 diversification both in blades and in veins. Trans-caftaric acid (the main phenolic acid) percentage

423 incidence was generally stable during the season or it decreased in a few genotypes (Figure 5). The proanthocyanidin profile evolved during the season in a genotype-specific manner in blades;

425

426

427

428

429

430

431

432

433

434

435

436

437

438

439

440

441

442

443

444

445 oppositely, it did not change in veins (Figure 7).

No major differences were noticed in relation to the flavone profile evolution in Vitis berlandieri and in Börner during the season.

Table 4. Eigenvectors of eleven variables (polyphenols in leaf blades) on the first three principal components (PRIN1, PRIN2 and PRIN3).

\begin{tabular}{lccc}
\hline & PRIN1 & PRIN2 & PRIN3 \\
$\begin{array}{l}\text { Myricetin glycosides (glucoside }+ \\
\text { glucuronide) }\end{array}$ & -0.25 & $\mathbf{0 . 5 1}$ & -0.05 \\
Protocatechuic acid-glucoside & -0.24 & -0.04 & 0.20 \\
Dihydroquercetin-hexoside & -0.14 & -0.32 & 0.36 \\
Fertaric acid + coutaric acid isomer & $\mathbf{- 0 . 4 0}$ & 0.34 & -0.02 \\
Caftaric acids (cis + trans) & $\mathbf{0 . 4 1}$ & 0.33 & -014 \\
Coutaric acids (cis + trans) & 0.30 & 0.02 & -0.02 \\
Flavones & 0.26 & -0.03 & $\mathbf{- 0 . 4 3}$ \\
Total phenolic acids & 0.33 & 0.44 & -0.15 \\
Total flavonols & -0.14 & $\mathbf{0 . 4 6}$ & 0.43 \\
Total flavan-3-ols & 0.30 & 0.08 & $\mathbf{0 . 5 5}$ \\
Dimeric proanthocyanidins & $\mathbf{0 . 4 3}$ & 0.03 & 0.34 \\
Eigenvalues & 3.56 & 2.57 & 1.79 \\
Total variance & 0.32 & 0.23 & 0.16 \\
\hline
\end{tabular}

Eigenvalues of the three PRINs and their contribution to total variance. In bold letters, the variables associated to the appropriate PRIN. 


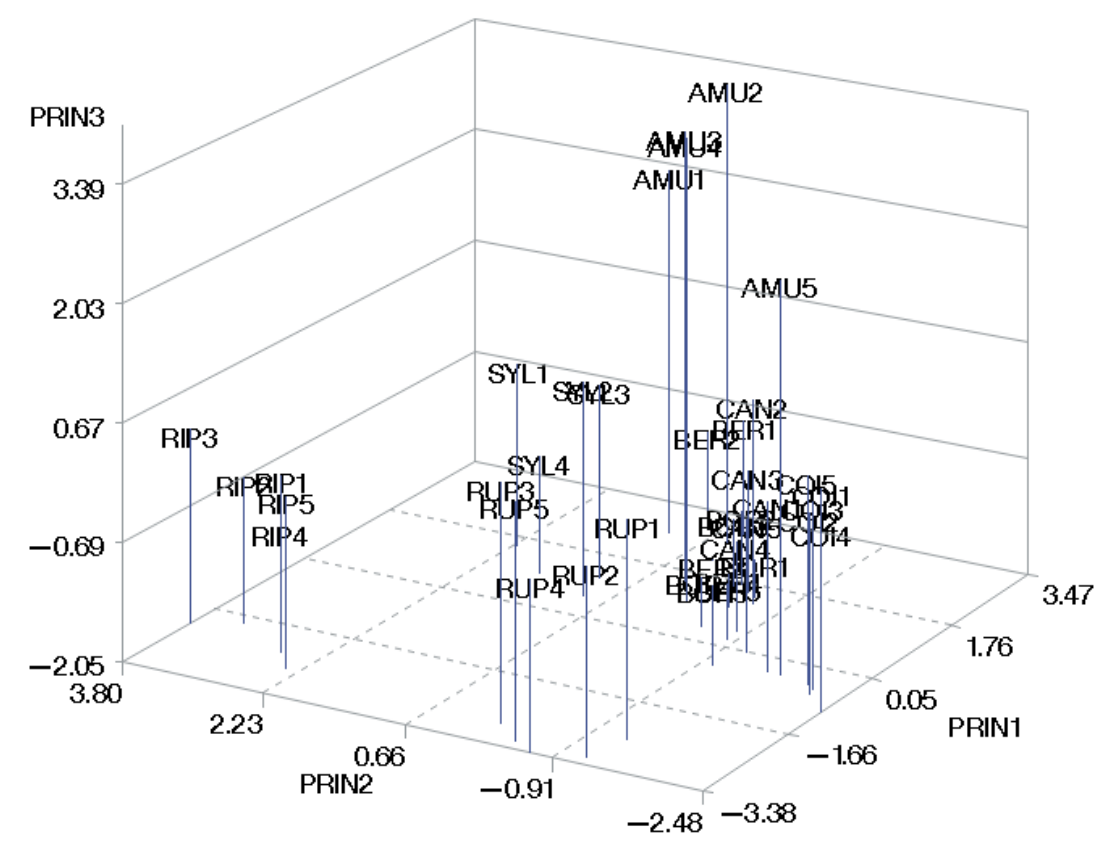

446

447 Figure 10. Tridimensional distribution of Vitis species during the vegetative season (1 to 5) on the first 448 three principal components, obtained by polyphenol quantifications and profiles of leaf blade extracts (see Table 4 for the list of used variables).

Table 5. Eigenvectors of nine variables (polyphenols in leaf veins) on the first three principal components (PRIN1, PRIN2 and PRIN3).

\begin{tabular}{lccc}
\hline & PRIN1 & PRIN2 & PRIN3 \\
Total polyphenols & $\mathbf{0 . 5 0}$ & 0.11 & -0.14 \\
Total phenolic acids & 0.36 & $\mathbf{0 . 3 9}$ & 0.25 \\
Total flavan-3-ols & $\mathbf{0 . 3 8}$ & 0.32 & 0.38 \\
Dimeric proanthocyanidins & 0.30 & -0.30 & $\mathbf{0 . 5 2}$ \\
Total flavanonols & 0.18 & $\mathbf{- 0 . 5 6}$ & 0.21 \\
Total flavones & -0.22 & 0.35 & 0.28 \\
Sum of glucuronide flavonols & $\mathbf{0 . 3 8}$ & 0.14 & -0.33 \\
Sum of glucoside flavonols & 0.36 & -0.38 & -0.29 \\
Sum of rhamnoside flavonols & 0.15 & 0.21 & -0.42 \\
Eigenvalues & 3.27 & 2.17 & 1.34 \\
Total variance & 0.36 & 0.24 & 0.15
\end{tabular}

Eigenvalues of the three PRINs and their contribution to total variance. In bold letters, the variables associated to the appropriate PRIN. 


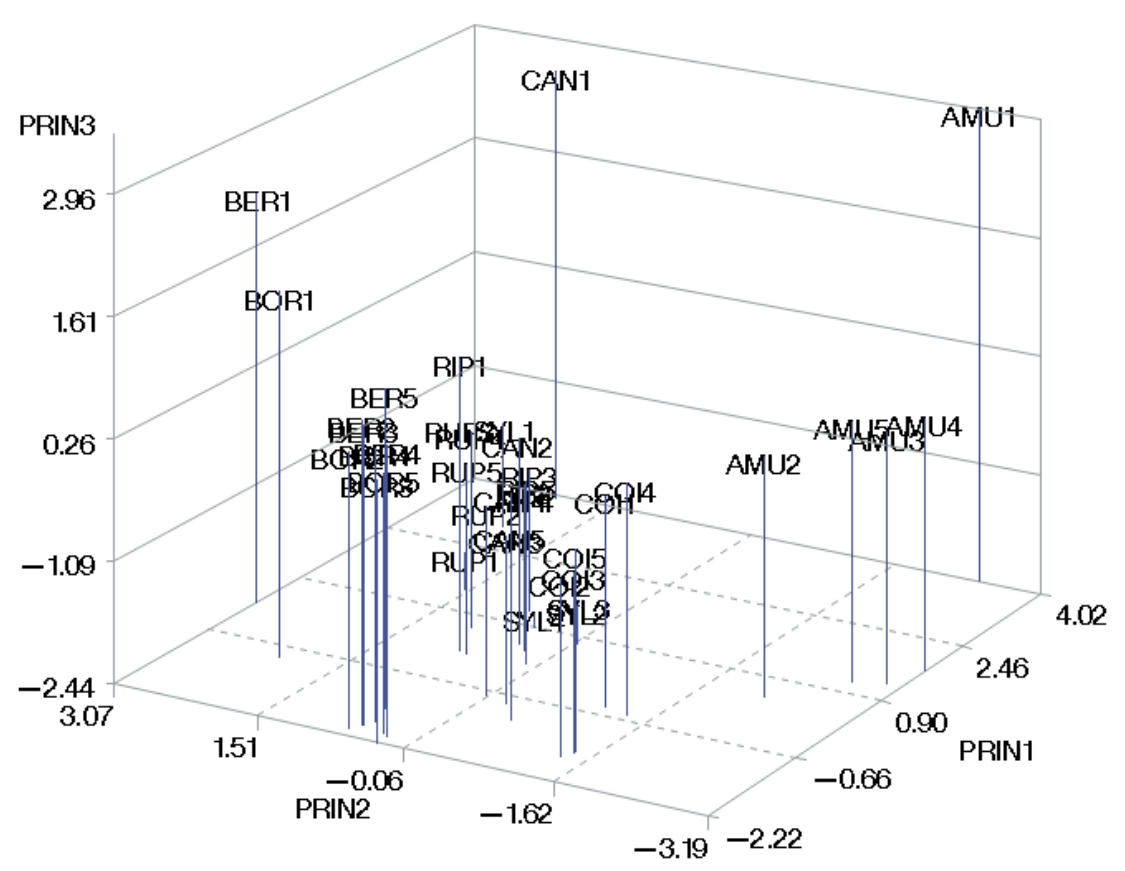

Figure 11. Tridimensional distribution of Vitis species during the vegetative season (1 to 5) on the first three principal components, obtained by polyphenol quantifications and profiles of leaf vein extracts (see Table 5 for the list of variables used).

\section{DISCUSSION}

There is increasing interest in grapevine leaf polyphenols to deepen knowledge about their biological role in plant-defense mechanisms and to answer to the growing demand of natural bioactive compounds for the feed/food, pharmaceutical and cosmetic sectors. Grapevine leaves are already employed in the production of food ingredients, dietary supplements, pharmaceutical products and medicated cosmetics (Dani et al., 2010). The evolution of the polyphenolic composition of eight Vitis genotypes during the vegetative season allowed pointing out significant qualitative and quantitative differences.

\subsection{Genotype-related specific traits of leaf polyphenols}

The two studied American species, V. riparia and V. rupestris, belonging to the same subgeneric group of Ripariae (Table 1), involved in crossbreed of Regent, a cultivar displaying low susceptibility to Plasmopara viticola and to Erysiphe necator, shared common phenolic composition and accumulation trends. In particular, they showed similarities in the accumulation trend of total phenolic 
acids and total flavan-3-ols. Additionally, they displayed identical flavonol profiles (Figure 4). However, V. riparia accumulated higher concentration of total polyphenols, total flavonols and total phenolic acids respect to $V$. rupestris, which could justify its specifically high resistance to downy mildew, as both flavonols and phenolic acids have been associated with the ability to limit this pathogen diffusion (Ali et al., 2012). Moreover, V. riparia total flavonol concentration both in blades and in veins was the highest comparing to all the other analyzed genotypes, almost during the entire vegetative season (Figure $3)$.

The American genotypes Börner and $V$. berlandieri, known as low-susceptible to many diseases, were classified by Galet (1988) into the same subgeneric serie of Cinereae (Table 1). Their main leaf polyphenolic traits showed many similarities, such as the concentration and the accumulation trend of total polyphenols, total flavonols and total flavones, together with identical profiles of flavonols, proanthocyanidins and flavones. Therefore, Galet's classification based on plant morphology matched with phenol profile patterns of these two genotypes, suggesting a phylogenetic link between Vitis cinerea (Börner parent) and Vitis berlandieri. Flavones, bioactive compounds often extracted from medical and herbaceous plants and involved in plant signaling and defense responses (Jiang et al., 2016), were exclusively detected in Börner and in V. berlandieri, among the studied genotypes. In grapevine, they are generally considered as minor compounds mostly represented by luteolin, but in Börner and $V$. berlandieri leaves their concentration reached $5 \mathrm{~g} \mathrm{~kg}^{-1} \mathrm{DW}$ (Figure 9) and showed a much wider profile, consisting of five apigenin and luteolin derivatives: specifically, four of them were $C$-glycosides and et al., 2016). However, as most studies focused on biological activities of the more common plant $O$ glycosylated-flavonoids, further research is required on grapevine $C$-glycosylated derivative health beneficial effect. McNally et al. (2003) demonstrated that in cucumber $C$-flavones acted as phytoalexins in response to powdery mildew fungus Podosphaera xanthii and concentration increases of orientin and one $\mathrm{O}$-glycoside (Table 3; Figure 9). $\mathrm{C}$-glycoside flavonoids generally display higher antioxidant potential and better therapeutic properties compared to aglycons or to $O$-glycosylated flavonoids (Xiao isoorientin were reported to be induced by soil salinity in buckwheat (F. esculentum) (Yang et al., 2018). 
$V$. berlandieri and Börner were also similar in the fact that they did not accumulate kaempferol glycosides, in line with what was previously demonstrated in the grapevine series Cinerea (Moore and

\section{Giannasi, 1987).}

The Asian wild species $V$. coignetiae has been cultivated during the last two decades in Japan for wine, juice and jam making (Kamiya et al., 2018). V. coignetiae leaf extract showed a strong radicalscavenging activity and potential hepato-protective effect on nonalcoholic steatohepatitis in liver (Takayama et al., 2009). However, in V. coignetiae leaves of the present study, the concentration of leaf polyphenols was generally lower comparing to the other genotypes (Figure 2). V. coignetiae along with

$V$. amurensis and $V . v$. sylvestris was one of the few species which accumulated flavanonols; two flavanonol compounds were detected in V. coignetiae, dihydrokaempferol-hexoside in veins and dihydroquercetin-hexoside in both blades and veins (Figure 8A, B). Taxifolin (dihydroquercetin) glycoside is known to have anti-inflammatory activity (Kim et al., 2008) and potential positive effect on atopic dermatitis treatment (Ahn et al., 2010). its cold tolerance and disease resistance to downy mildew (Jürges et al., 2009), anthracnose and white rot (Li et al., 2008). The leaves of $V$. amurensis reached the highest concentration of total polyphenols and flavan-3-ols in blades, important amounts of flavonols, and the highest concentration of flavanonols in veins. V. amurensis leaves are used in conventional Chinese medicine and included in Korean herbal Pharmacopoeia (Chen et al., 2018). Moreover, leaf extracts showed antimicrobial activity against Streptococcus mutans and Streptococcus sanguis (Yim et al., 2010) and neuroprotective effect (Jeong et al., 2010). Bak et al. (2012, 2016) demonstrated that $V$. amurensis seed proanthocyanidins have hepato-protective and antioxidative properties and a possible chemopreventive role in humans hepatocarcinoma cells. In $V$. amurensis blades, concentration of total flavan-3-ols was significantly higher during the entire vegetative season comparing to the other genotypes (Figure 6A). Moreover, also the concentration of (-)-epicatechin was particularly high. This compound was previously individuated 
(as discussed in Kedrina-Okutan et al., 2018). In non-Vitis vinifera genotypes, (-)-epigallocatechin was additionally detected with increasing concentration during the vegetative season (Figure 6). published dimeric PA identification (Flamini, 2013). (Vagiri et al., 2017) reported a negative correlation between (-)-epigallocatechin and the presence of septoria leaf spot caused by Mycosphaerella ribis in black currant leaves. The high concentration of constitutive polyphenolic compounds throughout the season in $V$. amurensis leaves contributes to explain this biotype excellent ability to protect against adverse environmental condition (frost and diseases). Furthermore, the abundance of polyphenols in $V$. amurensis leaves emphasizes that this species has the potential for further use as a source of natural bioactive compounds for nutraceutical and pharmacological uses.

The polyphenolic composition of $V$. candicans leaves was studied here for the first time, to the best of our knowledge. This American species has been described as highly vigorous, highly resistant to downy mildew and tolerant to drought and salt (Ollat et al., 2016). V. candicans leaves displayed a low concentration of total polyphenols, total flavonols, but a relatively high concentration of proanthocyanidins and this genotype was among the few able to accumulate procyanidin $\mathrm{B}_{1}$ in veins (Figure 7). Procyanidin $\mathrm{B}_{1}$, the dimeric proanthocyanidin consisting in units of (-)-epicatechin and (+)catechin, has an ecological significance in protecting plants against pathogens, insect pests and larger herbivores (Dixon et al., 2005). For instance, previous studies demonstrated that B. cinerea remained quiescent in immature strawberry until B proanthocyanidins are present at an essential high concentration: this effect is related to the proanthocyanidin inhibitory potential of the fungal polygalacturonase (Jersch et al., 1989).

The Eurasian wild species $V . v$. sylvestris, the ancestor of the worldwide cultivated $V$. vinifera sativa, accumulated relatively high concentration of total polyphenols and total phenolic acids (Figure 2; Figure 5). Among phenolic acids, the predominant non-flavonoid polyphenols, caftaric acid was the prevalent form, representing up to $90 \%$ of total phenolic acids (Figure 5C), similarly to what was previously assessed in $V$. vinifera sativa leaves (Kedrina-Okutan et al., 2018). Caftaric acid is an 
important bioactive component found in chicory, in the medical plant Echinacea purpurea (Bel-Rhlid et al., 2012) and, in $V$. coignetiae juice, where it exhibited anti-mutagenic and anti-inflammatory properties (Kamiya et al., 2018). In V. v. sylvestris leaves, we found astilbin (Figure 8B), in concentrations that were in line with those found in Cabernet Sauvignon, Grenache, Shiraz and Barbera, that were much lower respect to those found in Nebbiolo and Pinot noir (Kedrina-Okutan et al., 2018). Additionally, V. v. sylvestris displayed the most complex flavonol profile (Figure 4). In V. v. sylvestris veins we identified and quantified seven flavonols out of the eight flavonol compounds chromatographically separated; $V$. v. sylvestris was the exclusive genotype that accumulated kaempferol 3-O-rhamnoside (Figure 4, Table 3) and, compared to $V$. vinifera sativa, it accumulated additional flavonol rhamnosides (kaempferol- and quercetin-3-O-rhamnoside), showing a wider flavonol-profile diversification.

The peculiar traits of individual Vitis species leaf polyphenolic compositions were highlighted by the proposed PCA models. In particular, V. riparia and V. rupestris displayed similar eigenvectors on PRIN1 and PRIN3, highlighting their similar concentrations of dimeric proanthocyanidins, similar percentage incidence of caftaric acid over total phenolic acids (on PRIN1) and similar concentration of flavan-3-ols on PRIN3 (Table 4; Figure 10). V. riparia sharply distinguished on PRIN2 due its high flavonol content (Figure 3A) and the highest percentage incidence of myricetin derivatives respect to the other analyzed genotypes (Figure 4). Flavonols allowed the species separation, also when considering their concentration: in fact, flavonol glucosides, together with flavanonols, allowed a sharp separation of $V$. amurensis samples and were negatively associated to the second PRIN of the vein PCA model (Figure 11; Table 5). Oppositely, V. berlandieri and Börner associated to positive values of PRIN2, with reduced amounts of flavonol-glucosides comparing to the other species. Quercetin 3-Oglucoronide was the prevalent flavonol in the analyzed genotypes, consistently with other studies on $V$. vinifera and V. labrusca leaves (Dresch et al., 2014; Kedrina-Okutan et al., 2018). The differences in the flavonol profile might be related to the genus Vitis evolution: in fact, evidences about the reduction in structural complexity and in molecule diversification were reported (Moore and Giannasi, 1994), and 
they were also ascribed to the flavonoid biosynthetic pathway, that was shown to have undergone a simplification during evolution, particularly in domesticated genotypes. Interestingly, $V . v$. sylvestris, which, being the wild form of $V . v$ sativa, underwent no or low selection pressure, showed the widest flavonol profile diversification and comprised high concentration of quercetin 3-O-rhamnoside (22\% of total flavonols); besides, $V v$. sylvestris also displayed a higher flavonol profile diversity respect to cultivated varieties of $V$. vinifera. Quercetin 3-O-rhamnoside was also found in $V$. berlandieri and in Börner. Hilbert et al. (2015) identified flavonol rhamnosides in berry skin extracts of $V$. cinerea, which is native to the United States and belongs to the subgeneric group of Cinereae (Galet, 1988), the same of $V$. berlandieri and Börner. Thus, flavonol rhamnosides seem to be genotype-specific compounds, therefore they have the potential to be exploited as specific markers of some species and/or subspecies. Vein flavanonol concentration, associated to PRIN2 (Figure 11; Table 5) allowed the sharp separation of $V$. amurensis, and, secondarily the separation of $V$. coignetiae and $V$. v. sylvestris. Since flavanonols accumulate prevalently in leaf veins, their concentration on a per whole leaf basis is supposed to be low, considering the limited percentage incidence of veins on the total leaf area, but the role of these tissue-specific compounds arouses the interest about their interaction with vein-located pathogens. In some $V$. vinifera sativa varieties, we previously identified these molecules, particularly in veins (Kedrina-Okutan et al., 2018) where astilbin was the predominant compound. We also associated astilbin accumulation to a possible defense-mechanism in cv Nebbiolo (Ferrandino et al., 2019). In fact, in Nebbiolo leaves of plants affected by Flavescence dorée (FD), we found a significantly higher concentration of flavanonols compared to healthy vines, hypothesizing a possible capability to limit the pathogen development. Interestingly, together with $V$. v. sylvestris, also $V$. amurensis, whose capability to defend against pathogens is detailed and $V$. coignetiae, known for its strong antiradical role, accumulate flavanonols.

As to the ecological role of leaf polyphenols, further studies would be of extreme interest to understand: i) if genotype-related molecules such as flavanonols and flavones have specific capacities 
to limit diseases, starting from in vitro trials, ii) if grapevine plants can be induced to produce specific molecules, once demonstrated that they can efficaciously serve to limit pathogen development. As to the nutraceutical, pharmaceutical and feed/food ingredients, grapevine leaf are a source of bioactive compounds that in future could be economically exploited, also exploiting their wide and still little investigated, biodiversity.

ACKNOWLEDGMENTS. Authors gratefully acknowledge Tiziano Strano, DISAFA, University of Turin, for managing the collection vineyard. Financial support from 'Ricerca locale 2016 Caratterizzazione polifenolica di foglie di vite', University of Turin.

\section{REFERENCES}

Abascal, K., Ganora, L., Yarnell, E., 2005. The effect of freeze-drying and its implications for botanical medicine: a review. Phyther. Res. 19, 655-660. https://doi.org/10.1002/ptr.1651

Ahn, J.Y., Choi, S.E., Jeong, M.S., Park, K.H., Moon, N.J., Joo, S.S., Lee, C.S., Choi, Y.W., Kapsok, L., Lee, M.-K., Lee, M.W., Seo, J.S., 2010. Effect of taxifolin glycoside on atopic dermatitis-like skin lesions in NC/Nga mice. Phyther. Res. 24, 1071-1077. https://doi.org/10.1002/ptr

Ali, K., Maltese, F., Figueiredo, A., Rex, M., Margarida, A., Zyprian, E., Salomé, M., Verpoorte, R., Choi, Y.H., 2012. Alterations in grapevine leaf metabolism upon inoculation with Plasmopara viticola in different time-points. Plant Sci. 191-192, 100-107. https://doi.org/10.1016/j.plantsci.2012.04.014

Bak, M., Jun, M., Jeong, W., 2012. Procyanidins from wild grape (Vitis amurensis) seeds regulate AREmediated enzyme expression via Nrf2 coupled with p38 and PI3K/Akt pathway in HepG2 cells 801-818. https://doi.org/10.3390/ijms13010801

Bak, M.J., Truong, V.-L., Ko, S.-Y., Nguyen, X.N.G., Ingkasupart, P., Jun, M., Shin, J.Y., Jeong, W.S., 2016. Antioxidant and hepatoprotective effects of procyanidins from wild grape (Vitis 
amurensis) seeds in ethanol-induced cells and rats. Int. J. Mol. 17, 758. https://doi.org/10.3390/ijms17050758

Bel-Rhlid, R., Page-Zoerkler, N., Fumeaux, R., Ho-Dac, T., Chuat, J.-Y., Sauvageat, J.L., Raab, T., 2012. Hydrolysis of chicoric and caftaric acids with esterases and Lactobacillus johnsonii in vitro and in a gastrointestinal model. J. Agric. Food Chem. 60, 9236-9241. https://doi.org/10.1021/jf301317h

Chen, Q., Diao, L., Song, H., Zhu, X., 2018. Vitis amurensis Rupr: A review of chemistry and pharmacology. Phytomedicine 49, 111-122. https://doi.org/10.1016/j.phymed.2017.08.013

Dani, C., Oliboni, L.S., Agostini, F., Funchal, C., Serafini, L., Henriques, J.A., Salvador, M., 2010. Phenolic content of grapevine leaves (Vitis labrusca var. Bordo) and its neuroprotective effect against peroxide damage. Toxicol. Vitr. 24, 148-153. https://doi.org/10.1016/j.tiv.2009.08.006

Di Stefano, R., Cravero, M.C., 1992. The separation of hydroxycinnamates in wine. Sci. des Aliment. $139-144$.

Dixon, R., Xie, D.-Y., Sharma, S.B., 2005. Proanthocyanidins - a final frontier in flavonoid research? New Phytol. 165, 9-28.

Dixon, R.A., 2001. Natural products and plant disease resistance. Nature 411, 843-847. https://doi.org/10.1038/35081178

Dresch, R.R., Dresch, M.K., Guerreiro, A.F., Biegelmeyer, R., Holzschuh, M.H., Rambo, D.F., Henriques, A.T., 2014. Phenolic compounds from the leaves of Vitis labrusca and Vitis vinifera L. as a source of waste byproducts: development and validation of LC method and antichemotactic activity. Food Anal. Methods 7, 527-539. https://doi.org/10.1007/s12161-013-9650-4

Ferrandino, A., Guidoni, S., 2010. Anthocyanins, flavonols and hydroxycinnamates: An attempt to use them to discriminate Vitis vinifera L. cv "Barbera" clones. Eur. Food Res. Technol. 230, 417-427. 
663

664

665

666

667

668

669

670

671

672

673

674

675

676

677

678

679

680

681

682

683

Ferrandino, A., Pagliarani, C., Kedrina-Okutan, O., Icardi, S., Bove, M., Lovisolo, C., Novello, V., Schubert, A., 2019. Non-anthocyanin polyphenols in healthy and Flavescence dorée infected Barbera and Nebbiolo leaves. BIO Web Conf. 03003, 1-5. https://doi.org/https://doi.org/10.1051/bioconf/20191303003

Flamini, R., 2013. Recent applications of mass spectrometry in the study of grape and wine polyphenols. ISRN Spectrosc. 2013, 45. https://doi.org/10.1155/2013/813563

Galet, P., 1988. In Cepages Et Vignobles De France [Grapes and vineyards of France], 2nd ed. Imprimerie Charles Dehan, Montpellier.

Gómez-Zeledón, J., Zipper, R., Spring, O., 2013. Assessment of phenotypic diversity of Plasmopara viticola on Vitis genotypes with different resistance. Crop Prot. 54, 221-228. https://doi.org/10.1016/j.cropro.2013.08.015

Hilbert, G., Temsamani, H., Bordenave, L., Pedrot, E., Chaher, N., Cluzet, S., Delaunay, J.C., Ollat, N., Delrot, S., Mérillon, J.M., Gomès, E., Richard, T., 2015. Flavonol profiles in berries of wild Vitis accessions using liquid chromatography coupled to mass spectrometry and nuclear magnetic resonance spectrometry. Food Chem. 169, 49-58. https://doi.org/10.1016/j.foodchem.2014.07.079

Hmamouchi, M., Es-Safi, N., Lahrichi, M., Fruchier, A., Essassi, E.M., 1996. Flavones and flavonols in leaves of some Moroccan Vitis vinifera cultivars. Am. J. Enol. Vitic. 47, 186-192. https://doi.org/10.1071/PP9960115

Jeong, H.Y., Kim, J.Y., Lee, H.K., Ha, D.T., Song, K.S., Bae, K., Seong, Y.H., 2010. Leaf and stem of Vitis amurensis and its active components protect against amyloid $\beta$ protein (25-35)-induced neurotoxicity. Arch. Pharm. Res. 33, 1655-1664. https://doi.org/10.1007/s12272-010-1015-6 
686

687

688

689

690

691

692

693

694

695

696

697

698

699

700

701

702

703

704

705

706

707

Jiang, N., Doseff, A., Grotewold, E., 2016. Flavones: from biosynthesis to health benefits. Plants 5, $27-$ 52. https://doi.org/10.3390/plants5020027

Jürges, G., Kassemeyer, H.H., Dürrenberger, M., Düggelin, M., Nick, P., 2009. The mode of interaction between Vitis and Plasmopara viticola Berk. \& Curt. Ex de Bary depends on the host species. Plant Biol. 11, 886-898. https://doi.org/10.1111/j.1438-8677.2008.00182.x

Kamiya, T., Tanimoto, Y., Fujii, N., Negishi, T., Suzuki, T., Hatano, T., Arimoto-Kobayashi, S., 2018. 2,6-Dimethoxy-1,4-benzoquinone, isolation and identification of anti-carcinogenic, anti-mutagenic and anti-inflammatory component from the juice of Vitis coignetiae. Food Chem. Toxicol. 122, 172-180. https://doi.org/10.1016/j.fct.2018.10.028

Kedrina-Okutan, O., Novello, V., Hoffmann, T., Hadersdorfer, J., Occhipinti, A., Schwab, W.G., Ferrandino, A., 2018. Constitutive polyphenols in blades and veins of grapevine (Vitis vinifera L.) healthy leaves. J. Agric. Food Chem. 66, 10977-10990. https://doi.org/10.1021/acs.jafc.8b03418

Kim, B., Woo, S., Kim, M.J., Kwon, S.W., Lee, J., Sung, S.H., Koh, H.J., 2018. Identification and quantification of flavonoids in yellow grain mutant of rice (Oryza sativa L.). Food Chem. 241, 154-162. https://doi.org/10.1016/j.foodchem.2017.08.089

Kim, Y.J., Choi, S.E., Lee, M.W., Lee, C.S., 2008. Taxifolin glycoside inhibits dendritic cell responses stimulated by lipopolysaccharide and lipoteichoic acid. J. Pharm. Pharmacol. 60, 1465-1472. https://doi.org/10.1211/jpp/60.11.0007

Li, D., Wan, Y., Wang, Y., He, P., 2008. Relatedness of resistance to anthracnose and to white rot in Chinese wild grapes. Vitis 47, 213-215. https://doi.org/10.1073/pnas.96.3.1146

Li, Z.H., Guo, H., Xu, W. Bin, Ge, J., Li, X., Alimu, M., He, D.J., 2016. Rapid identification of flavonoid constituents directly from PTP1B inhibitive extract of raspberry (Rubus idaeus L.) leaves by 

HPLC-ESI-QTOF-MS-MS.

J. Chromatogr.

Sci.

54, 805-810. https://doi.org/10.1093/chromsci/bmw016

Llorens, E., García-Agustín, P., Lapeña, L., 2017. Advances in induced resistance by natural compounds: towards new options for woody crop protection. Sci. Agric. 74, 90-100. https://doi.org/10.1590/1678-992x-2016-0012

McNally, D.J., Wurms, K. V., Labbé, C., Bélanger, R.R., 2003. Synthesis of $C$-glycosyl flavonoid phytoalexins as a site-specific response to fungal penetration in cucumber. Physiol. Mol. Plant Pathol. 63, 293-303. https://doi.org/10.1016/j.pmpp.2004.03.005

Moore, M.O., Giannasi, D.E., 1994. Foliar flavonoids of eastern North American Vitis (Vitaceae) north of Mexico. Plant Syst. Evol. 193, 21-36.

Moore, M.O., Giannasi, D.E., 1987. Foliar flavonoids of selected Vitis taxa in the Southeastern United States. Biochem Syst Ecol 15, 79-83.

Ollat, N., Bordenave, L., Tandonnet, J.P., Boursiquot, J.M., Marguerit, E., 2016. Grapevine rootstocks: origins and perspectives. Acta Hortic. 1136, 11-22. https://doi.org/10.17660/ActaHortic.2016.1136.2

Pastrana-Bonilla, E., Akoh, C.C., Sellappan, S., Krewer, G., 2003. Phenolic content and antioxidant capacity of muscadine grapes. J. Agric. Food Chem. 51, 5497-5503. https://doi.org/10.1021/jf030113c

Ruel, J.R., Walker, M.A., 2006. Resistance to Pierce's disease in Muscadinia rotundifolia and other native grape species. Am. J. Enol. Vitic. 32, 155-158.

Singleton, V.L., Orthofer, R., Lamuela-Raventós, R.M., 1999. Analysis of total phenols and other oxidation substrates and antioxidants by means of Folin-Ciocalteu reagent. Methods Enzymol. 299, 152-178. https://doi.org/10.1016/S0076-6879(99)99017-1 
Staudt, G., 1997. Evaluation of resistance to grapevine powdery mildew (Uncinula necator [Scxw.] Burr., anamorph Oidium tuckeri BERK.) in accessions of Vitis species. Vitis 36, 151-154.

Takayama, F., Nakamoto, K., Kawasaki, H., Mankura, M., Egashira, T., Ueki, K., Hasegawa, A., Okada, S., Mori, A., 2009. Beneficial effects of Vitis coignetiae Pulliat leaves on nonalcoholic steatohepatitis in a rat model. Acta Med. Okayama 63, 105-111. https://doi.org/10.18926/AMO/31835

Vagiri, M., Johansson, E., Rumpunen, K., 2017. Phenolic compounds in black currant leaves - an interaction between the plant and foliar diseases? J. Plant Interact. 12, 193-199. https://doi.org/10.1080/17429145.2017.1316524

Wan, Y., Schwaninger, H., He, P., Wang, Y., 2007. Comparison of resistance to powdery mildew and downy mildew in Chinese wild grapes. Vitis 46, 132-136.

Wan, Y., Schwaninger, H.R., Baldo, A.M., Labate, J.A., Zhong, G.Y., Simon, C.J., 2013. A phylogenetic analysis of the grape genus (Vitis L.) reveals broad reticulation and concurrent diversification during neogene and quaternary climate change. BMC Evol. Biol. 13, 141-161. https://doi.org/10.1186/1471-2148-13-141

Xiao, J., Capanoglu, E., Jassbi, A.R., Miron, A., 2016. Advance on the flavonoid C-glycosides and health benefits. Crit. Rev. Food Sci. Nutr. 56, 29-45. https://doi.org/10.1080/10408398.2015.1067595

Yang, L., Wen, K.S., Ruan, X., Zhao, Y.X., Wei, F., Wang, Q., 2018. Response of plant secondary $\begin{array}{lllll}\text { metabolites to } & \text { environmental } & \text { factors. }\end{array}$ https://doi.org/10.3390/molecules23040762

Yim, N., Thi, D., Nam, T., Pyo, J., Lee, S., Na, M., Jung, H., Su, H., Ho, Y., Bae, K., 2010. Bioorganic \& Medicinal Chemistry Letters The antimicrobial activity of compounds from the leaf and stem of Vitis amurensis against two oral pathogens. Bioorg. Med. Chem. Lett. 20, 1165-1168. 
756 Zhang, J., Wu, X., Niu, R., Liu, Y., Liu, N., Xu, W., Wang, Y., 2012. Cold-resistance evaluation in 25

757 wild grape species. Vitis

J. Grapevine

Res.

4, 153-160.

$758 \quad$ https://doi.org/10.1017/S0020743810001558

759 